\title{
PERCEPCCÃO DE RADIAÇÕES IONIZANTES POR INSETOS
}

\author{
CLAYTON CAMPANHOLA
}

Orientador: Julio Marcos Melges Walder

\begin{abstract}
Dissertação apresentada à Escola Superior de Agriculfura "Luiz de Queiroz", da Universidade de São Paulo, para obtenção do tífulo de Mestre em Energia Nuclear na Agricultura.
\end{abstract}

\author{
$P|R A C| C A B A$
}

Estado de São Paulo - Brasil

Abril, 1980 
MEUS PAIS E IRMAOS

DE D I C O. 


\section{AGRADECIMENTOS}

- Ao Dr. Julio Marcos Melges Walder, a orientação e amizade.

- A minha esposa Silvia de Toledo Compconhola, a compreensão e boa vontade com que cedeu nossas horas de lazer.

- Aos Drs. Frederico Maximiliano Wiendl e Ricardo Bohrer Sgrizlo, as criticas e sugestões.

- Ao Dr. Humberto de Compos, o auxílio na oção das anālises estatísticas.

- Ao Dr. Francisco de Assis Menezes Mariconi, o interesse e entusiasmo com que sempre me recebeu.

- A Dra. Elza Flores Rüegg, a compreensão e apoio.

- A Dra. Diva Athié, pe la versão do resumo em inglès.

- Aos comigos da Seção de Entomologia do CENA, a sol idariedade.

- Ao Centro de Energia Nuclear na Agmicultura, as facilidades concedidas.

- A Comissão Nacional de Energia Nuclear, o suporte financeiro.

- A todos que, direta ou indiretamente, contribuíram para o éxito des te trabalho.

- A Deus, por ter-me dado forças nas horas difíceis. 


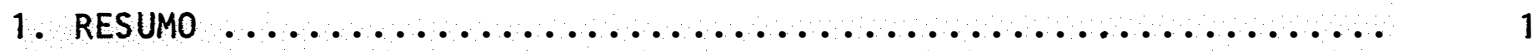

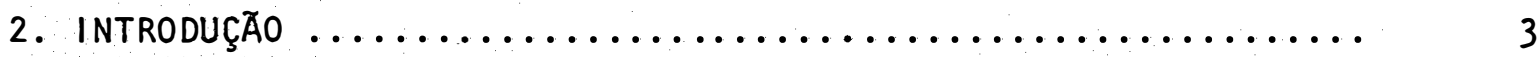

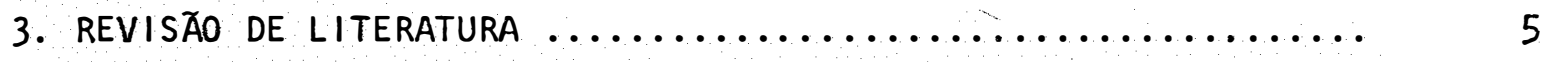

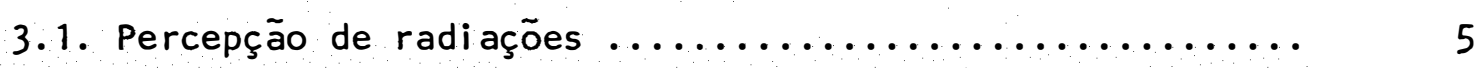

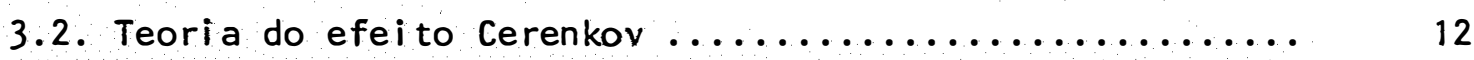

3.3. Sensibilidade luminosa espectral dos insetos ......... 16

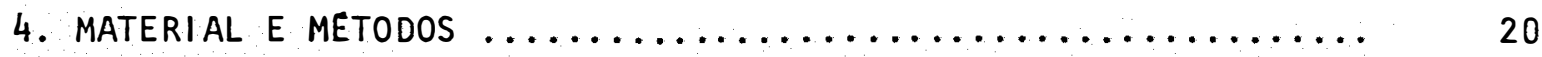

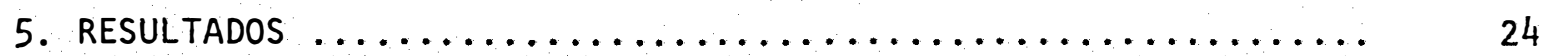

6. ANALISE DOS RESULTADOS E DISCUSSÃO $\ldots \ldots \ldots \ldots \ldots \ldots \ldots \ldots \ldots \ldots \ldots \ldots \ldots \ldots \ldots \ldots$

6.1. Tes tes estatisticos utilizados $\ldots \ldots \ldots \ldots \ldots \ldots \ldots \ldots . \quad 52$

6.2. Resultados dos testes estatísticos e discussão para as diferentes espëcies $\ldots \ldots \ldots \ldots \ldots \ldots \ldots \ldots \ldots \ldots \ldots . . \ldots \ldots$

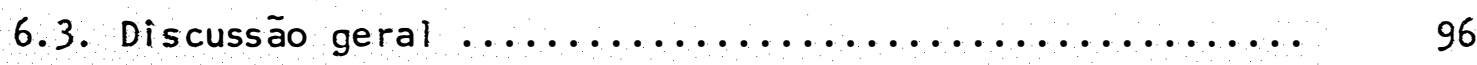

7. CONCLUS $\tilde{E}$

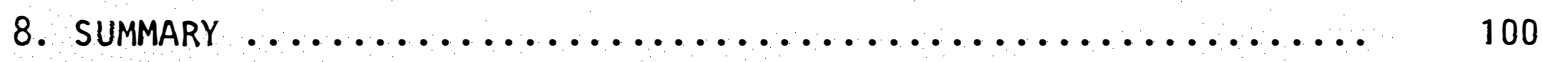

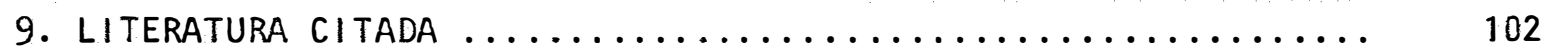




\section{RESUMO}

Com este trabalho procurou-se constatar a existência de per cepçao de radiações ionizantes por insetos e esclarecer sobre o mecanismo através do qual ela se processa. Outro objetivo é averiguar se a percepção induz a um afastamento dos insetos da fonte radioativa, evidenciando uma proteção aos danos causados pelas radiações ionizantes, ou se o estímu lo de comportamento é similar àquele provocado por radiações luminosas.

Como fontes de radiações gama utilizou-se o ${ }^{60} \mathrm{Co}$ e o ${ }^{241} \mathrm{Am}$, estando a fonte de ${ }^{60} \mathrm{Co} \operatorname{com} 0,435 \mathrm{mCi}$ e a de ${ }^{241} \mathrm{Am}$ com $99,68 \mathrm{mCi}$ de atividade. Os insetos adultos das espécies Acanthoscelides obtectus (Say, 1831), Zabrotes subfasciatus (Boh., 1833), Callosobruchus analis (Fabr., 1775), Sitophilus oryzal (L., 1763), Ephestia cautella (Walker, 1864), Tri bolium castaneum (Herbst, 1797), Ceratitis capitata (wied., 1824) e operárias de Atta bisphaerica Forel, 1908 e Camponotus rufipes (Fabr., 1775) foram utilizados nos seguintes tratamentos: exposição às radiações do ${ }^{60}$ Co 
$e^{242} \mathrm{Am}$ e ausência de exposição (testemunhal.

Os insetos, num total de aproximadamente 50 por repetição, foram liberados na região central de uma arena de madeira branco opaco dividida em 3 setores de mesma área, com 60,0 cm de diámetro e 7,5 cm de altura, coberta com telado de náilon. Efetuaram-se 5 repetições por trata mento e a distribuição dos insetos foi avaliada por meio de fotografias ti radas a 15, 30, 45 e 60 minutos após a soltura.

As espécies Zabrotes subfasciatus (Boh., 1833), Acanthoscelides obtectus (Say, 1831), Callosobruchus analis (Fabr., 1775), Tribolium castaneum (Herbst, 1797), Camponotus rufipes (Fabr., 1775), Ceratitis capi tata (Wied., 1824) e Atta bisphaerica Forel, 1908 não apresentaram respos tas comportamentais passíveis de generalizações em relação às radiações gama do ${ }^{241} \mathrm{Am}$ e ${ }^{60} \mathrm{Co}$. Porém, as espécies Sitophilus oryzae (L., 1763) e Ephestia cautella (Walker, 1864) apresentaram alguma resposta às radiações gama do ${ }^{241} \mathrm{Am}$, a qual foi da mesma natureza que a provocada pela luz, ou seja, tatismo negativo.

Concluiu-se que as radiações ionizantes podem ser detectadas pelos insetos ou por estímulo visual direto, ou por estímulo visual através de produção de radiações Cerenkov, resultantes da interação das radiações com outro componente ocular, de maior índice de refração que a àgua. E também que, na percepção de radiações ionizantes pelos insetos, a atividade da fonte radioativa foi relevante em comparação com a energia das radiações emitidas pela mesma ou, em outros termos, o que importa é a dose absorvida de radiações. 


\section{INTRODUÇÃO}

Muitos autores efetuaram estudos alusivos à resposta de insetos a radiações ionizantes, como GOLDHABER e FELDMAN-MUHSAM (1944), SMITH et alii (1963), SMITH e KDMELDORF (1964), BROWER (1967), MARTINSEN E KIMELDORF (1972), WIENDL (1972) e WIENDL e WALDER (1975). Porém, pouco se conhece do mecanismo ou processo através do qual as radiações ionizantes são perceptíveis, bem como da natureza da resposta comportamental provocada por estas radiações em insetos.

Um dos objetivos a que se propõe este estudo é a constatação da existência ou não de perceptividade às radiações ionizantes pelos insetos. Caso haja percepção, será verificado se esta se processa através de estímulo visual direto ou se através de efeitos secundários, resultantes da interação das radiações ionizantes com a matéria. Um processo viável seria aquele em que os fotoelétrons e elétrons Compton, provenientes da interação das radiações gama com os componentes do olho dos insetos, ricos em 
agua, originariam fótons na faixa do ultravioleta e luz visível denominados radiações Cerenkov. Estes fótons seriam captados pelo rabdoma e se consti tuiriam en estímulo visual.

Dutro objetivo deste trabalho é averiguar se a percepção induz a um afastamento dos insetos da fonte radioativa, evidenciando uma proteção aos danos causados pelas radiações ionizantes, ou se o estímulo de comportamento é similar àquele provocado por radiações luminosas.

Um afastamento em relação à fonte de radiações pode-se constituir em problema na desinfestação de grãos e produtos armazenados. Os insetos, migrando para regiões onde as taxas de dose são mais baixas, se submetem, no tempo previsto de exposição, a uma dose subesterilizante, contribuindo assim, para um controle ineficiente. 


\section{REVISAOO DE LITERATURA}

Devido à sua heterogeneidade, este ítem foi subdividido em trés, quais sejam: percepção de radiações, teoria do efeito Cerenkov e sensibilidade luminosa espectral dos insetos.

\subsection{Percepção de radiações}

Estudos relativos à percepção de radiações por animais, de um modo geral, são relativamente recentes.

E fato conhecido desde a metade do século, que radiações ionizantes podem agir como estímulo de luz em relação ao sistema visual de ho mens e rãs (LIPETZ, 1955 a). As doses efetivas de radiações para estimular o sistema visual destas espécies parecem ser relativamente pequenas. Ainda LIPETZ (1955 b) observou descargas elétricas em células de gànglio da retina de rãs "in situ" quando o olho era estimulado por raios $X$, deter- 
minando que a dose limiar para esse efeito foi $156 \mathrm{mR}$ a uma taxa de $0,78 \mathrm{R} /$ seg.

HUG (1960), segundo SMITH et alii (1963), identificou algumas reações às radiações ionizantes em invertebrados marinhos, tais como re tração de tentáculos, fechamento de conchas ou migração para áreas expostas a baixa intensidade de radiação. Ainda SMITH et alii (1963) revelaram outros autores envolvidos nesse tipo de pesquisa, como KREBS (1961) e SCARBOROUGH e ADDISON (1962), que, trabalhando com, respectivamente, tartarugas e peixes, constataram a ocorréncia de distúrbios imediatos no comportamento desses animais provocados por fontes de alta intensidade de radiação gama.

Através do levantamento do eletroretinograma por meio de estímulos de raios $\mathrm{X}$ em rãs, BACHOFER e WITTRY (1962) encontraram que o limi ar de obtenção de um potencial de pico foi de, aproximadamente, $7 \mathrm{mR}$ a 162 R/seg e que o limiar de taxa de dose para obtenção de uma resposta no eletroretinograma, com adaptação anterior do olho ao escuro, foi de $0,001 \mathrm{R} /$ seg durante 3 a 4 segundos.

BROWER (1967) citou que KIMELDORF e HUNT (1965), em experimentos de laboratório, demonstraram que certos animais vertebrados podem perceber, aparentemente, as radiações e tendem a evitá-las.

Contudo, são raras as referências que visam a identificação do mecanismo fisiológico pelo qual os estímulos de raios $X$ provocam respostas comportamentais em artrópodos. Alguns estudos têm enfatizado os fotoreceptores como responsáveis por esse processo. TERWILLIGER e LEVY (1964), 
por exemplo, observaram que caranguejos não exibiram respostas de comportamento a raios $X$ quando seus olhos foram extirpados.

o primeiro trabalho relacionado com percepção de radiações ionizantes por insetos foi desenvolvido por GOLDHABER e FELDMAN-MUHSAM (1964). Estes autores efetuaram experimento com larvas e pupas do mosquito Aedes aegypti (L.) utilizando uma fonte de raios $X$. 0 número de movimentos por minuto foi tomado como uma indicação da atividade. Esta, antes do início da irradiação, variou de 30 a 80 movimentos por minuto, para dife rentes indivíduos. Com uma intensidade de $38.000 \mathrm{R} / \mathrm{min}$, pode ser notada a diferença de atividade entre diferentes indivíduos durante sucessivas irradiações de 1 minuto alternadas com interrupções de mesma duração. A ati vidade aumentou de 20 a 60 movimentos por minuto, durante a irradiação. Ne nhuma suposição relacionada com o processo de percepção dos raios $X$ pelas larvas e pupas de Aedes aegypti (L.) foi feita pelos autores.

BROWER (1967) comentou que HUG (1960) se referiu a uma resposta de aversão a radiações exibida por formigas submetidas a baixas taxas de exposição.

Baseando-se no fato de que muitas espécies demonstraran uma resposta imediata de comportamento quando submetidas às radiações ionizantes, SMITH et aZii (1963) efetuaram testes com mariposas, 8 espécies de Noctuidae e uma de Arctiidae, com o intuito de avaliar a sensibilidade desses insetos à baixa intensidade de radiação, utilizando uma fonte de raios X. Após a adaptação ao escuro por 4 minutos, cada espécime foi submetido ao menos 3 vezes às taxas de 0,$33 ; 0,13 ; 0,10$ e 0,07 R/seg. A duração 
da exposição variou de 1 a 15 segundos e o tempo entre exposições flutuou entre vários segundos a 3 minutos.

Os resultados mostraram uma resposta dos insetos à exposição aos raios $X$ através de movimento de asas ou mudança na amplitude do movimen to durante o vōo. As taxas de dose, em R/seg, para iniciar essa ação nas diferentes espécies foram: Crymodes devastator (Brace), 0,50; Protorthodes rufula [Grote1, 0,37; Agrotis ypsilon (Rottemberg), 0,01; Agrotis ypsilon (Rottembergl, 0,01; Agrotis ypsilon (Rottemberg), 0,12; Agrotis subterranea (Fabricius), 0,20; Acronicta mormorota (Smith), 0,10; Catocala irene (Behr), 0,17; C. irene (Behrl, 1,50; Prodenia praefica (Grote), 0,17; Ma mestra configurata (Walker), 0,33 e Halisidota maculata (Harris), 0, 33. № ta-se que existem grandes disparidades no limiar para diferentes preparações dentro de uma mesma espécie e, obviamente, entre espécies diferentes.

Esses pesquisadores concluíram que fica difícil obter um efeito da ação das radiações em fibras musculares, em vista da baixa dose de exposição e da pequena latência. Salientaram também que a resposta motora pode ser obtida somente quando o espécime permanece em local escuro por vários minutos, podendo ser a indução da atividade de vōo uma consequiência do estímulo visual provocado pela baixa intensidade de radiação.

SMITH e KTMELDORF (1964) fizeram comparações entre radiações beta e luz como estímulo ao sistema visual dos noctuideos Pseudaletia unipuncta e Agrotis ypsilon, utilizando 3 fontes de radiações beta de 22, 50 e $87 \mathrm{mCi}$ de ${ }^{90} \mathrm{Sr}$ e uma lámpada de tungsténio de 6 Volts e 1,8 "meter-candles" de iluminação. Além de outros estudos, esses autores determinaram a taxa 
de dose limiar para uma resposta às radiações beta, com a fonte de 22 mCi. As taxas variaram de 0,02 e 0,06 R/seg para diferentes espécies e preparações distintas de uma mesma espécie. O limiar encontrado foi $20 \mathrm{mR} / \mathrm{seg}$, a uma dose de $0,25 \mathrm{mR}$.

Smith e Kimeldorf concluíram que as radiações beta podem ori ginar um eletroretinograma de olho de mariposa igual ao produzido pelo estí mulo luminoso e que o pigmento atenuador é transparente às radiações ioni zantes, mas atenua o estímulo luminoso. Comentaram não estar claro se a ação das radiações beta é sobre o receptor ou se é devida a um efeito secun dário de fluorescência causado pelas radiações.

Na floresta experimental de Brookhaven, EUA, com uma fonte de ${ }^{137}$ Cs de 9.500 Ci em seu centro, BROWER (1967) estudou os efeitos das ra diações gama, a uma taxa de $200 \mathrm{R} / \mathrm{dia}$, em uma colónia de formigas Formíca integra Nyl. 0 autor observou modificações nos hábitos desses insetos e sugeriu que tal comportamento tenha-se relacionado com as radiações e seus efeitos. Entretanto, as mudanças na comunidade causadas pelas radiações complicaram a interpretação; a construção de uma trilha em direção oposta à fonte pode ter sido induzida pela abundância de alimentos nessa região. Contudo, deve-se lembrar que a trilha serviu para reduzir o nivel de exposi ção ao longo de seu comprimento e na área de coleta de forragens. o hábito de amontoar entulhos na base do toco de madeira onde se encontrava o ninho foi abandonado.

observações durante o mesmo período de tempo ( 3 anos) em outras colónias afastadas da fonte de radiações não revelaram mudanças simila 
res às observadas. Portanto, supõe-se que as alterações estejam relaciona das com a exposição às radiações gama.

Em um estudo teórico envolvendo a sensibilidade de insetos às radiações, CALLAHAN (1967) referiu-se ao fato de que as características dos olhos e espinhos sensitivos favorecem a comunicação entre os insetos por meio de radiações infravermelho e microondas. 0 objetivo foi obter o processo pelo qual os insetos se relacionam com as radiações eletromagnéticas totais de seu meio ambiente, ou seja, os transdutores que coletam e amplificam a energia do ambiente ou de outros insetos e a transferem para o sistema nervoso.

Teoricamente, Callahan provou que tanto as substâncias cerosas que revestem a cutícula dos insetos, como seu próprio exoesqueleto, apresentam eficientes propriedades termoelétricas, isto é, podem ser submeti dos à ação simultânea de calor Cinfravermelhol e campo elétrico. Esses efeitos podem ser, posteriormente, transmitidos ao sistema nervoso. Esse pesquisador concluiu ainda que os olhos compostos e os ocelos de mariposas podem ser considerados como detectores de radiações infravermelho incoerentes e os espinhos (antenas tubulares dielétricas), como receptores de infra vermelho coerentes.

MARTINSEN e KTMELDORF (1972) verificaram que a taxa 'limiar de exposição a raios $X$ para provocar uma resposta bioelétrica no olho de formigas Camponotus herculeanus foi menor que $300 \mathrm{mR} / \mathrm{seg}$. A perda de resposta ao estímulo por radiações beta do ${ }^{9} \mathrm{Sr}(100$ ou $50 \mathrm{mCi})$ foi irreversível e pareceu depender da dose total absorvida. 
Os autores observaram que os mecanismos de ação de partículas beta no olho podem diferir daqueles de fótons visíveis e raios $x$. Apesar das diferenças inexplicáveis entre as respostas eletroretinográficas de raios $X$ e radiações beta, constataram que, sob condições de adaptação ao escuro, os olhos das formigas detectaram a presença de fótons de alta energia e elétrons. Tal detecção, entretanto, não iniciou uma reação com portamental imediata das formigas aos raios $X$. Mesmo assim, respostas imediatas no comportamento foram observadas com taxas de exposição a raios $X$ tão baixas como $0,05 \mathrm{R} / \mathrm{seg}$.

Estes autores foram, provavelmente, os primeiros a se certi ficarem de que os receptores dos olhos e antenas são detectores de radiações ionizantes. Por exemplo, estimativas de limiar de exposições ou doses, liberadas em frações de 1 segundo, indicaram que os receptores dos oIhos e antenas da formiga Camponotus herculeanus podem detectar raios $x e$ radiações beta da ordem de mrad.

Um dos estudos mais recentes relacionados com a percepção de radiações gama por insetos foi desenvolvido por WIENDL e WALDER (1975) com adultos de Sitophilus zeamais Mots.

Esses pesquisadores dispuseram tubos de locomoção de lucite com $1 \mathrm{~m}$ de comprimento, radialmente a uma fonte gama de ${ }^{6}{ }^{0} \mathrm{Co}$ de $650 \mathrm{Ci}$ e, imediatamente após as sucessivas irradiações, fizeram contagens dos indiví duos a diversas distáncias da fonte. Compararam a distribuição dos insetos submetidos à ação das radiações com a do tratamento testemunha Isem fonte radioatival, concluindo que Sitophilus zeamais Mots. percepta radia- 
ções gama e que a mesma se traduz por locomoção em direção oposta à fonte radioativa.

Como explicação, Wiendl e Walder aventaram a hipótese de ser possível uma influência direta das radiações sobre os órgãos visuais, haven do ainda a possibilidade de existir uma relação entre esse fato e o efeito Cerenkov proveniente da interação das radiações com a água existente nas cé lulas: oculares.

\subsection{Teoria do efeito Cerenkov}

0 efeito Cerenkov foi descrito detalhadamente por vários autores, entre eles MARSHALL (1952), JELLEY (1953, 1958), HUTCHINSON (1960) e MOYER (1962), segundo NASCIMENTO FILHO (1975).

Simplificadamente, o efeito Cerenkov se traduz por radiações produzidas quando uma partícula carregada atravessa um meio transparente com uma velocidade maior que a velocidade da luz nesse mesmo meio. A partícula fica sujeita a uma forte força de desaceleração e, durante esse período de rápida desaceleração, radiações eletromagnéticas são geradas.

A condição limiar para a formação de radiação Cerenkov é:

$$
\beta \cdot \eta=1
$$

onde: $\beta=\frac{\text { velocidade da partícula (v) }}{\text { velocidade da luz (c) }}$ 
$\eta$ = indice de refração do meio transparente.

Através da mecânica relativística, $\beta$ pode ser relacionado com a energia cinética da partícula $(T)$ :

$$
T=m_{0} c^{2}\left[\frac{1}{\sqrt{1-\beta^{2}}}-1\right]
$$

onde: $m_{0} c^{2}=$ massa de repouso da partícula carregada.

No caso de radiações gama, estas interagem com materiais de número atómico baixo, como a água, por efeitos Compton e fotoelétrico. Os elétrons Compton predominam em relação aos fotoelétrons para radiações gama pouco energéticas.

Os olhos compostos dos insetos apresentam constituintes com elevado teor de água. Para elétrons, o limiar de energia para a ocorrência de efeito Cerenkov na água $(\eta=1,33)$ é de $263 \mathrm{keV}(R O S S, 1969$; ROSS e RASMUSSEN, 1974; NASCIMENTO FILHO, 1975; GELSEMA et alii, 1975). Assim, os elétrons Compton e os fotoelétrons gerados pela interação das radiações gama com a matéria devem possuir energia cinética maior que $263 \mathrm{keV}$.

Pela teoria de Frank e Tamm, segundo ROSS (1969) e PARKER e ELRICK (1970), pode-se obter o número de fótons produzidos por unidade de comprimento percorrida por um elétron em uma determinada região do es pectro: 


$$
\frac{d N}{d x}=2 \pi \frac{e^{2}}{h c}\left(\frac{1}{\lambda_{2}}-\frac{1}{\lambda_{1}}\right)\left(1-\frac{1}{B^{2} \cdot n^{2}}\right)(\text { fótons } / \mathrm{cm}]
$$

onde: $\frac{d N}{d x}=n^{2}$ de fótons emitidos por unidade de percurso de elétron;

$$
\begin{aligned}
\lambda_{1} & =\text { limite inferior da faixa espectral considerada; } \\
\lambda_{2} & =\text { limite superior da faixa espectral considerada; } \\
\text { e } & =\text { carga eletrónica } \\
\mathrm{h} & =\text { constante de Planck } \\
c, \beta, \Pi & =\text { definidos anteriormente. }
\end{aligned}
$$

Para determinar-se a produção total de fótons de um certo evento Cerenkov, a equação (3) seria normalmente integrada nos limites de $x$, ou seja, o percurso da partícula. Entretanto, a equação não pode ser usada, porque a distáncia percorrida pela partícula varia com a sua energia inicial e torna-se uma variável durante o percurso.

o número de fótons emitidos por elétrons na água, em função de sua energia inicial, consta da Tabela 1.

Pelos dados observados, nota-se a predominância de fótons na região do ultravioleta e azul, independentemente da energia do elétron.

Como ficou comprovado, a produção de ondas eletromagnéticas pelo efeito Cerenkov depende somente da energia da partícula carregada, para um mesmo meio transparente. Contudo, NASCIMENTO FILHO (1975) ressalta que se um radioisótopo emissor de partículas beta de alta energia estiver 


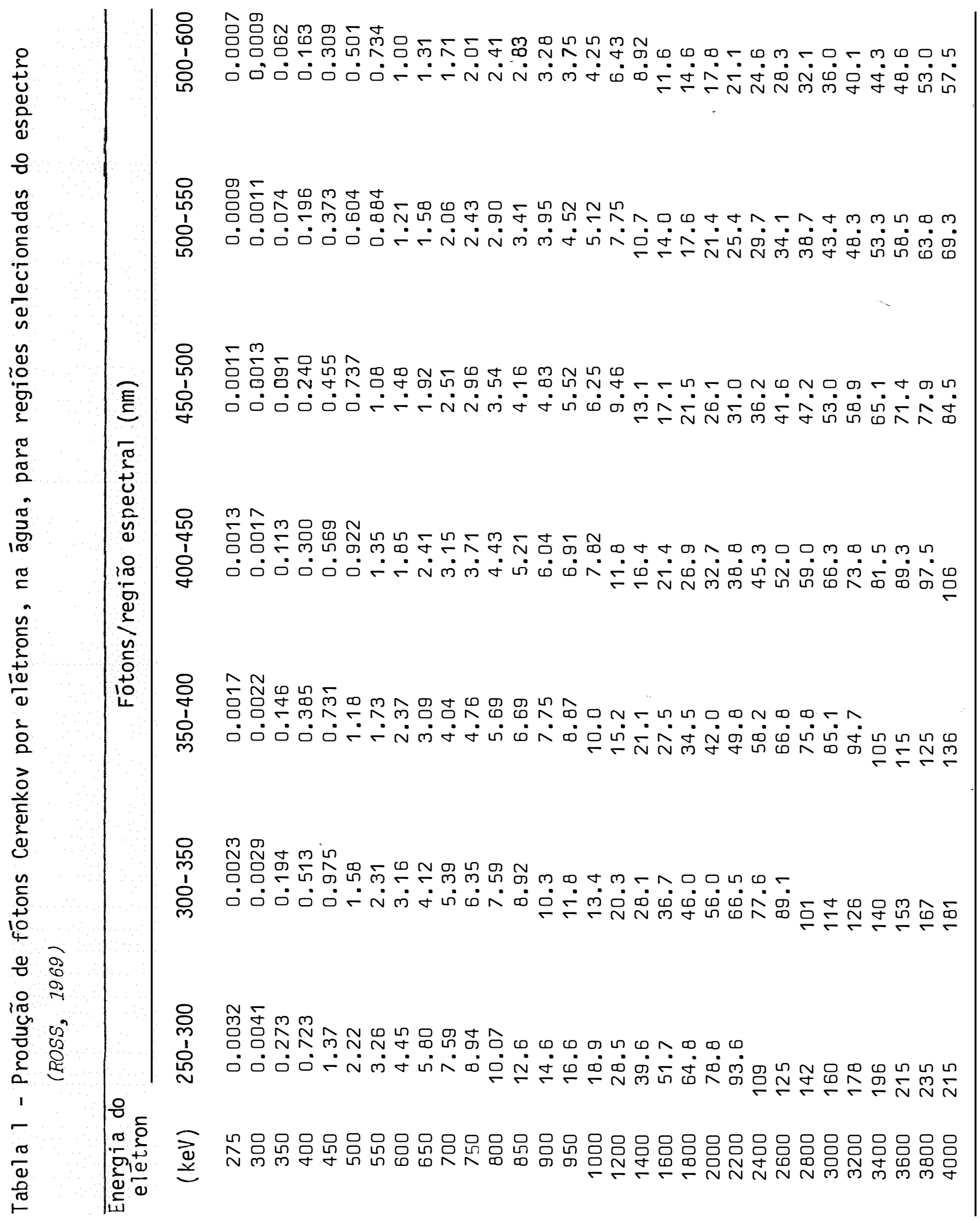


contido em um meio colorido Camarelo, por exemplol ou que tenha uma faixa ou pico de absorção na região ultravioleta (íons nitrato e nitrito), os fótons produzidos poderão ser absorvidos por este próprio meio. Isto acarre ta uma diminuição da eficiência de detecção.

\subsection{Sensibilidade luminosa espectral dos insetos}

Devido ao fato da interação por efeito Cerenkov na água gerar fótons com uma distribuição espectral, torna-se necessário conhecer a sensibilidade luminosa espectral dos insetos visando-se avaliar se existe coincidéncia entre a faixa de maior emissão de fótons Cerenkov com os picos de sensibilidade apresentados pelos ol hos dos insetos.

A sensibilidade ao espectro luminoso demonstrada por insetos começou a ser elucidada há poucas décadas.

BERTHOLF (1931) procurou generalizar a região de espectro lu minoso mais sensivel aos animais, constatando que ela se encontra entre a regịão do azul-verde e amarelo, ou seja, entre 473 e $580 \mathrm{~nm}$, dependendo do animal.

Ainda BERTHOLF (1931) obteve que, para abelhas, a eficiência máxima de estímulo visual está no comprimento de onda $553 \mathrm{~nm}$, que correspon de exatamente ao ponto de maior sensibilidade para o homem.

STERMER (1959) citou que estudos conduzidos por GUI et alii 
1942), TAYLOR e DEAY (1950) e GLICK et alii (1955) indicaram que certos insetos demonstraram maior resposta para os menores comprimentos de onda do espectro luminoso. Entretanto, WEISS et alii (1942) mostraram que uma mudança na intensidade alterou a resposta espectral de várias espécies de insetos.

Em seu experimento, STERMER (1959) determinou a resposta espectral dos insetos: Sitophilus oryzae (L.), Sitotroga cerealellaloliv.), Ephestia cautella (Walker), Rhyzopertha dominica (F.), Tribolium castaneum (Herbst), Plodia interpunctella (Hon.) e Laemophloeus minutus (oliv.). Es se autor constatou uma reação fototática negativa para todas as espécies, tendo a mesma aumentado significativamente com um aumento da intensidade luminosa. Entretanto, houve alguma discrepância en relação aos picos de maior sensibilidade, quando comparados com outros trabalhos. 0 pico de maior resposta esteve ao redor de $500 \mathrm{~nm}$ para muitas espécies.

Stermer observou também que todas as espécies testadas exibí ram uma baixa resposta a $60 \mathrm{~nm}$ e praticamente nenhuma resposta a $280,4 \mathrm{~nm}$. Por fim, ele salientou o fato de que uma variação na intensidade luminosa não alterou a resposta espectral, atribuindo as discrepancias existentes em relação a outros autores, tais como WEISS et alii (1942), como uma provável falta de confecimento, por parte deles, da intensidade luminosa exata para cada comprimento de onda considerado.

De acordo com GALLO et alii (1970), a maioria dos insetos tem um pico de resposta à luz monocromática em 365 nm e um pico secundārio entre 492 e $515 \mathrm{~nm}$. 
Segundo BURSELL (1970), tem sido demonstrada a existéncia de dois pigmentos distintos no olho dos insetos: um com o pico de $340 \mathrm{~nm}$ (ultravioleta) e outro com um pico de $540 \mathrm{~nm}$ [verde-amarelo]. Em moscas, tem sido possivel investigar a sensibilidade espectral de células sensoriais isoladas usando-se eletrodos intracelulares. Todas as células testadas mos traram um pico de $350 \mathrm{~nm}$, mas enquanto algumas tinham um pico secundário em $450 \mathrm{~nm}$, outras o tinham em 480 e $520 \mathrm{~nm}$.

YINON (1970) referiu-se ao fato de que em Tenebrio molitor L. uma mudança na intensidade luminosa alterou somente o nível de resposta, observação essa que concorda com a de STERMER (1959). Tenebrio molitor L. foi sensitivo a comprimentos de onda entre 350 e 700 nm, com uma resposta máxima entre 520 e $540 \mathrm{~nm}$.

MARZKE et alii (1973) investigaram as respostas espectrais dos olhos compostos de seis espécies de insetos de produtos armazenados,por levantamento de eletroretinogramas de olhos adaptados ao escuro. Em geral, os insetos demonstraram maior sensibilidade a comprimentos de onda entre 475 e $600 \mathrm{~nm}$. Concluíram que para os insetos testados, Tribolium confusum duVal, Tineola bisselliella (Humme1), Trogoderma glabrum (Herbst), Sitotroga cerealella COliv.l, Plodia interpunctella (Hbn) e Lasioderma serriconne (F.), os olhos compostos foram sensíveis a comprimentos de onda menores que $600 \mathrm{~nm}$, na região visível.

O eletroretinograma também foi usado por PHILLIS e AGEE (1976) para determinar a sensibilidade espectral do olho de mosca dos estábulos. $\quad 0$ olho apresentou sensibilidade máxima em 490 nm, um pico secundá- 
rio próximo a $350 \mathrm{~nm}$ e um pequeno pico terciário em $625 \mathrm{~nm}$. Tais resultados, segundo os próprios autores, foram semelhantes àqueles encontrados por GOLDSMITH E FERNANDEZ (1968).

Nota-se, portanto, pelos trabalhos comentados, que os insetos geralmente apresentam um pico de sensibilidade em torno de $500 \mathrm{~nm}$ (verde) e um outro em torno de $350 \mathrm{~nm}$ (ultravioletal. Assim, pode-se notar pela Tabela 1, que a faixa de maior emissão de radiação Cerenkov coincide com o pico de sensibilidade na faixa do ultravioleta, apresentado pela maioria dos insetos. 


\section{MATERIAL E METODOS}

o presente trabalho foi desenvolvido na Seção de Entomologia do Centro de Energia Nuclear na Agricultura (CENA), Piracicaba (SP).

$$
\text { Como fontes de radiações gama foram utilizados o }{ }^{60} \mathrm{Co} \text { e o }
$$

${ }^{241} \mathrm{Am}$. A fonte de ${ }^{60} \mathrm{Co}$, com $0,435 \mathrm{mCi}$, foi obtida da Tracerlab (EUA) e a de ${ }^{241} \mathrm{Am}$, com 99,68 mCi, da Amersham (Inglaterral, ambas de propriedade do CENA: As radiações gama do ${ }^{241} \mathrm{Am}$ apresentam energia de $0,060 \mathrm{MeV}$ e as do ${ }^{60} \mathrm{Co}, 1,332$ e 1,173 MeV. Nota-se que os elétrons Compton e os fotoelé trons resultantes da interação das radiações gama do ${ }^{241} \mathrm{Am}$ com a ägua ocular dos insetos têm energia menor que $0,263 \mathrm{MeV}$, a qual é o limiar para ocorrência do efeito Cerenkov na água, ao passo que as radiações gama do ${ }^{60}$ Co, por interação com a água, produzem radiações Cerenkov.

Os insetos adultos das espécies Acanthoscelides abtectus (Say, 1831], Zabrotes subfasciatus (Boh., 1833), Callosobruchus analis 
[Fabr., 17751, Sitophilus oryzae [1., 1763), Ephestia cautella (Walker, 1864), Tribolium castaneum [Herbst, 1797) e Ceratitis capitata (Wied., 1824) foram obtidos da criação estoque da Seção de Entomologia do CENA, ao passo que operárias das espécies Atta bisphaerica Forel, 1908 e Camponotus rufipes (Fabr., 1775] foram coletadas no campo.

Os tratamentos constaram de exposições às radiações gama do ${ }^{60} \mathrm{Co}$ e ${ }^{241} \mathrm{Am}$ e auséncia de exposição (testemunha). Efetuaram-se 5 repetí ções por tratamento, sendo que cada repetição constou de aproximadamente 50 insetos adultos.

Os insetos foram liberados na região central de uma arena de madeira branco opaco com 60,0 cm de diâmetro e 7,5 cm de altura, cober ta com telaḑo de náilon. A arena foì dividida em 3 setores radiais de mesma área a partir da região de posicionamento das fontes radioativas.

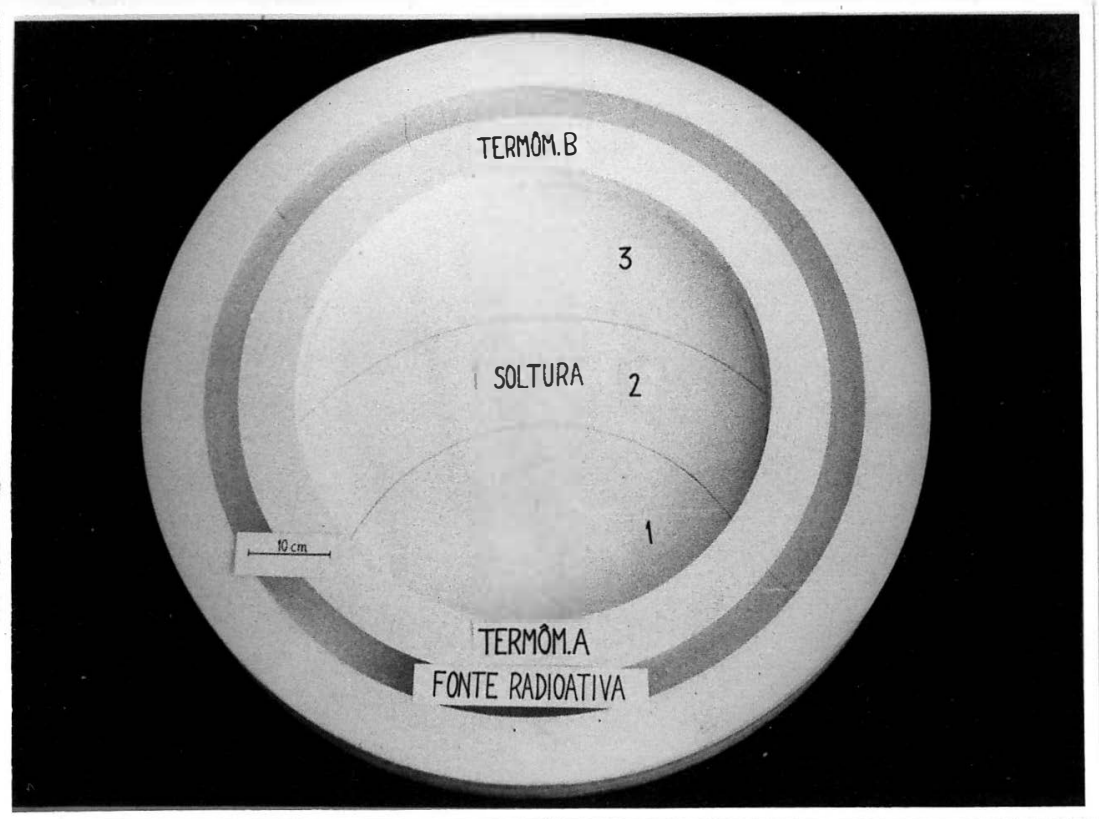

Figura 1 - Representação da arena 
Para a fonte de ${ }^{60}$ Co, as taxas de dose foram calculadas pelo manual do fabricante:

$$
\frac{\Delta x}{\Delta t}=\frac{A \cdot 13500}{D^{2}}
$$

onde: $\frac{\Delta x}{\Delta t}=$ taxa de exposição em $\mathrm{mR} / \mathrm{h}$

$$
\begin{aligned}
& A=\text { atividade da fonte em } \mathrm{mCi} \\
& D=\text { distáncia da fonte em } \mathrm{cm}
\end{aligned}
$$

As taxas variaram de $23,50 \mathrm{R} / \mathrm{h}$, na tela, a $7,08 \mathrm{mR} / \mathrm{h}$, no $\mathrm{p} i$ so, no setor 1 . De $7,60 \mathrm{mR} / \mathrm{h}$, na tela, a $3,15 \mathrm{mR} / \mathrm{h}$, no piso, no setor 2 e de $3,25 \mathrm{mR} / \mathrm{h}$, na tela, a $1,60 \mathrm{mR} / \mathrm{h}$, no piso, no setor 3 .

Na presença das radiações do ${ }^{241} \mathrm{Am}$, as taxas de dose, considerando-se a fonte como pontual, foram calculadas através da equação:

$$
\frac{\Delta x}{\Delta t}=\frac{\Gamma \cdot A}{D^{2}}
$$

$$
\text { onde: } \begin{aligned}
\frac{\Delta x}{\Delta t} & =\text { taxa de exposição em } \mathrm{mR} / \mathrm{h} \\
\Gamma & =\text { constante dos raios gama em } \mathrm{m}^{2} \cdot \mathrm{R} / \mathrm{Ci} \cdot \mathrm{h} \\
\mathrm{A} & =\text { atividade em } \mathrm{mCi} \\
D & =\text { distância da fonte } \mathrm{em} \mathrm{m}
\end{aligned}
$$

Houve variação da taxa no setor 1 de 139,55 R/h, na tela, a 42, a9 mR/h, no piso. No setor 2 , de $45,14 \mathrm{mR} / \mathrm{h}$, na tela, a $18,73 \mathrm{mR} / \mathrm{h}$, 
no piso e no setor 3 de 19,32 mR/h, na tela, a 9,54 mR/h, no piso.

Com o intuito de se avaliar a distribuição dos insetos, foram tiradas fotografias com auxílio de "flash" a 15, 30, 45 e 60 minutos após a soltura. Nestes mesmos tempos efetuou-se a leitura dos 2 termómetros. A contagem dos insetos em cada setor foi feita no negativo dos fil mes, com auxílio de lupa binocular.

O experimento se desenvolveu em câmara de ambiente controla do a $25 \pm 5^{\circ} \mathrm{C}$ e $70 \pm 5 \%$ de umidade relativa, com 3 lámpadas vermelhas de $60 \mathrm{~W}$, em triángulo, a dois metros de altura da arena. As lámpadas foram acesas somente para a tirada das fotografias e leitura dos termómetros. 


\section{RESULTADOS}

As contagens dos insetos adultos em cada setor da arena para as espécies consideradas, na presença das fontes de ${ }^{241} \mathrm{Am}$ e ${ }^{60}$ Co e na auséncia de fonte radioativa, encontram-se nas tabelas de números 2 a 28 . Saliente-se que o número de insetos contados nem sempre foi igual a 50 , pois a geometria do sistema impediu que todos fossem fotografados.

As diferenças entre as leituras dos dois termômetros, num mesmo tempo, foram iguais ou inferiores a $5^{\circ} \mathrm{C}$, para todos os tratamentos e espécies estudadas. 
Tabela 2 - Distribuição, em relação ao tempo, de adultos da espécie Zabrotes subfasciatus (Boh., 1833) por setor da arena, para a fonte de ${ }^{241} \mathrm{Am}$.

\begin{tabular}{|c|c|c|c|c|}
\hline \multirow{2}{*}{ Repetição } & \multirow{2}{*}{$\begin{array}{l}\text { Tempo } \\
\text { (min) }\end{array}$} & \multicolumn{3}{|c|}{ Setor } \\
\hline & & 1 & 2 & 3 \\
\hline \multirow[t]{4}{*}{1} & 15 & 6 & 11 & 14 \\
\hline & 30 & 8 & $\theta$ & 9 \\
\hline & 45 & 13 & 3 & 10 \\
\hline & 60 & 13 & 9 & 8 \\
\hline \multirow[t]{4}{*}{2} & 15 & 10 & 12 & 9 \\
\hline & 30 & 14 & 10 & 6 \\
\hline & 45 & 19 & 8 & 10 \\
\hline & 60 & 18 & $\theta$ & 11 \\
\hline \multirow[t]{4}{*}{3} & 15 & 12 & 10 & 6 \\
\hline & 30 & 14 & 10 & 11 \\
\hline & 45 & 10 & 9 & 15 \\
\hline & 60 & 15 & 9 & 13 \\
\hline \multirow[t]{4}{*}{4} & 15 & 6 & 8 & 6 \\
\hline & 30 & 7 & 9 & 7 \\
\hline & 45 & 10 & 8 & 11 \\
\hline & 60 & 13 & 12 & 4 \\
\hline \multirow[t]{4}{*}{5.} & 15 & 7 & 14 & 6 \\
\hline & 30 & 7 & 13 & 4 \\
\hline & 45 & 7 & 12 & 2 \\
\hline & 60 & 9 & 8 & 7 \\
\hline
\end{tabular}


Tabela 3 - Distribuição, em relação ao tempo, de adultos da espécie Zabro-: tes subfasciatus (Boh., 1833) por setor da arena, para a fonte de ${ }^{60} \mathrm{Co}$

\begin{tabular}{|c|c|c|c|c|}
\hline \multirow{2}{*}{ Repetição } & \multirow{2}{*}{$\begin{array}{l}\text { Tempo } \\
\text { (min) }\end{array}$} & \multicolumn{3}{|c|}{ Setor } \\
\hline & & 1 & 2 & 3 \\
\hline \multirow[t]{4}{*}{1} & 15 & 10 & 15 & 7 \\
\hline & 30 & 12 & 12 & 11 \\
\hline & 45 & 6 & 15 & 14 \\
\hline & 60 & 13 & 15 & 11 \\
\hline \multirow[t]{4}{*}{2} & 15 & 9 & 8 & 11 \\
\hline & 30 & 9 & 11 & 13 \\
\hline & 45 & 5 & 18 & 16 \\
\hline & 60 & 13 & 7 & 18 \\
\hline \multirow[t]{4}{*}{3} & 15 & 4 & 6 & 14 \\
\hline & 30 & 8 & 4 & 14 \\
\hline & 45 & 4 & 4 & 24 \\
\hline & 60 & 9 & 4 & 19 \\
\hline \multirow[t]{4}{*}{4} & 15 & 5 & 12 & 12 \\
\hline & 30 & 8 & 9 & 11 \\
\hline & 45 & 5 & 8 & 14 \\
\hline & 60 & 9 & 11 & 10 \\
\hline \multirow[t]{4}{*}{5} & 15 & 2 & 26 & 4 \\
\hline & 30 & 10 & 20 & 6 \\
\hline & 45 & 11 & 18 & 12 \\
\hline & 60 & 17 & 15 & 9 \\
\hline
\end{tabular}


Tabela 4 - Distribuição, em relação ao tempo, de adultos da espécie Zabrotes subfasciatus (Boh., 1833) por setor da arena, na ausēncia de fonte radioativa (test.)

\begin{tabular}{|c|c|c|c|c|}
\hline \multirow{2}{*}{ Repetição } & \multirow{2}{*}{$\begin{array}{l}\text { Tempo } \\
\text { (min) }\end{array}$} & \multicolumn{3}{|c|}{ Setor } \\
\hline & & 1 & 2 & 3 \\
\hline \multirow[t]{4}{*}{1} & 15 & 7 & 10 & 8 \\
\hline & 30 & 7 & 12 & 12 \\
\hline & 45 & 17 & 8 & 10 \\
\hline & 60 & 8 & 13 & 14 \\
\hline \multirow[t]{4}{*}{2} & 15 & 7 & 8 & 8 \\
\hline & 30 & 14 & 8 & 11 \\
\hline & 45 & 20 & 9 & 8 \\
\hline & 60 & 9 & 13 & 9 \\
\hline \multirow[t]{4}{*}{3} & 15 & 5 & 24 & 7 \\
\hline & 30 & 5 & 16 & 7 \\
\hline & 45 & 2 & 10 & 13 \\
\hline & 60 & 9 & 15 & 12 \\
\hline \multirow[t]{4}{*}{4} & 15 & 6 & 23 & 9 \\
\hline & 30 & 10 & 12 & 13 \\
\hline & 45 & 11 & 9 & 17 \\
\hline & 60 & 14 & 11 & 17 \\
\hline \multirow[t]{4}{*}{5} & 15 & 8 & 11 & 14 \\
\hline & 30 & 8 & 11 & 12 \\
\hline & 45 & 11 & 11 & 9 \\
\hline & 60 & 18 & 10 & 8 \\
\hline
\end{tabular}


Tabela 5 - Distribuịção, em relação ao tempo, de adultos da espécie Acanthoscelides obtectus (Say, 1831), por setor da arena, para a fonte de ${ }^{241} \mathrm{Am}$

\begin{tabular}{|c|c|c|c|c|}
\hline \multirow{2}{*}{ Repetição } & \multirow{2}{*}{$\begin{array}{l}\text { Tempo } \\
\text { (min) }\end{array}$} & \multicolumn{3}{|c|}{ Setor } \\
\hline & & 1 & 2 & 3 \\
\hline \multirow[t]{4}{*}{1} & 15 & 3 & 11 & 15 \\
\hline & 30 & 5 & 14 & 13 \\
\hline & 45 & 9 & 7 & 15 \\
\hline & 60 & 9 & 10 & 8 \\
\hline \multirow[t]{4}{*}{2} & 15 & 10 & 9 & 18 \\
\hline & 30 & 15 & 10 & 18 \\
\hline & 45 & 12 & 23 & 9 \\
\hline & 60 & 10 & 12 & 22 \\
\hline \multirow[t]{4}{*}{3} & 15 & 8 & 20 & 12 \\
\hline & 30 & 12 & 12 & 21 \\
\hline & 45 & 10 & 15 & 18 \\
\hline & 60 & 12 & 12 & 18 \\
\hline \multirow[t]{4}{*}{4} & 15 & 11 & 13 & 15 \\
\hline & 30 & 15 & 11 & 10 \\
\hline & 45 & 11 & 11 & 13 \\
\hline & 60 & 10 & 7 & 13 \\
\hline \multirow[t]{4}{*}{5} & 15 & 13 & 16 & 14 \\
\hline & 30 & 9 & 13 & 19 \\
\hline & 45 & 8 & 20 & 12 \\
\hline & 60 & 12 & 20 & 14 \\
\hline
\end{tabular}


Tabela 6 - Distribuição, em relação ao tempo, de adultos da espécie Acanthoscelides obtectus (Say, 1831) por setor da arena, para a fonte de ${ }^{60} \mathrm{Co}$.

\begin{tabular}{|c|c|c|c|c|}
\hline \multirow{2}{*}{ Repetição } & \multirow{2}{*}{$\begin{array}{l}\text { Tempo } \\
\text { (min) }\end{array}$} & \multicolumn{3}{|c|}{ Setor } \\
\hline & & 1 & 2 & 3 \\
\hline \multirow[t]{4}{*}{1} & 15 & 12 & 18 & 13 \\
\hline & 30 & 16 & 12 & 14 \\
\hline & 45 & 15 & 16 & 16 \\
\hline & 60 & 15 & 9 & 13 \\
\hline \multirow[t]{4}{*}{2} & 15 & 14 & 13 & 11 \\
\hline & 30 & 13 & 17 & 10 \\
\hline & 45 & 10 & 10 & 16 \\
\hline & 60 & 15 & 16 & 12 \\
\hline \multirow[t]{4}{*}{3} & 15 & 15 & 12 & 13 \\
\hline & 30 & 7 & 14 & 13 \\
\hline & 45 & 13 & 12 & 16 \\
\hline & 60 & 11 & 14 & 15 \\
\hline \multirow[t]{4}{*}{4} & 15 & 6 & 15 & 16 \\
\hline & 30 & 10 & 11 & 16 \\
\hline & 45 & 13 & 14 & 15 \\
\hline & 60 & 11 & 21 & 13 \\
\hline \multirow[t]{4}{*}{5} & 15 & 9 & 13 & 11 \\
\hline & 30 & 8 & 16 & 10 \\
\hline & 45 & 14 & 12 & 14 \\
\hline & 60 & 5 & 16 & 10 \\
\hline
\end{tabular}


Tabela 7 - Distribuição, em relação ao tempo, de adultos da espécìe Acanthoscelides obtectus (Say, 1831) por setor da arena, na ausēn cia de fonte radioativa (test.)

\begin{tabular}{|c|c|c|c|c|}
\hline \multirow{2}{*}{ Repetição } & \multirow{2}{*}{$\begin{array}{l}\text { Tempo } \\
\text { (min) }\end{array}$} & \multicolumn{3}{|c|}{ Setor } \\
\hline & & 1 & 2 & 3 \\
\hline \multirow[t]{4}{*}{1} & 15 & 10 & 13 & 18 \\
\hline & 30 & 8 & 15 & 15 \\
\hline & 45 & 11 & 15 & 18 \\
\hline & 60 & 1.6 & 15 & 13 \\
\hline \multirow[t]{4}{*}{2} & 15 & 8 & 14 & 19 \\
\hline & 30 & 12 & 12 & 20 \\
\hline & 45 & 13 & 16 & 13 \\
\hline & 60 & 16 & 17 & 15 \\
\hline \multirow[t]{4}{*}{3} & 15 & 10 & 10 & 14 \\
\hline & 30 & 9 & 12 & 15 \\
\hline & 45 & 11 & 13 & 16 \\
\hline & 60 & 8 & 14 & 16 \\
\hline \multirow[t]{4}{*}{4} & 15 & 6 & 14 & 7 \\
\hline & 30 & 6 & 11 & 19 \\
\hline & 45 & 10 & 12 & 17 \\
\hline & 60 & 9 & 12 & 15 \\
\hline \multirow[t]{4}{*}{5} & 15 & 17 & 6 & 21 \\
\hline & 30 & 16 & 9 & 17 \\
\hline & 45 & 15 & 7 & 15 \\
\hline & 60 & 12 & 13 & 16 \\
\hline
\end{tabular}


Tabela 8 - Distribuição, em relação ao tempo, de adultos da espécie Callosobruchus analis (Fabr., 1775), por setor da arena, para a fonte de ${ }^{241} \mathrm{Am}$

\begin{tabular}{|c|c|c|c|c|}
\hline \multirow{2}{*}{ Repetição } & \multirow{2}{*}{$\begin{array}{l}\text { Tempo } \\
(\min )\end{array}$} & \multicolumn{3}{|c|}{ Setor } \\
\hline & & 1 & 2 & 3 \\
\hline \multirow[t]{4}{*}{1} & 15 & 11 & 9 & 7 \\
\hline & 30 & 8 & 10 & 12 \\
\hline & 45 & 9 & 9 & 18 \\
\hline & 60 & 16 & 9 & 13 \\
\hline \multirow[t]{4}{*}{2} & 15 & 8 & 12 & 15 \\
\hline & 30 & 13 & 8 & 14 \\
\hline & 45 & 8 & 12 & 19 \\
\hline & 60 & 11 & 13 & 13 \\
\hline \multirow[t]{4}{*}{3} & 15 & 10 & 12 & 15 \\
\hline & 30 & 8 & 9 & 16 \\
\hline & 45 & 10 & 14 & 12 \\
\hline & 60 & 11 & 11 & 11 \\
\hline \multirow[t]{4}{*}{4} & 15 & 10 & 19 & 11 \\
\hline & 30 & 11 & 18 & 14 \\
\hline & 45 & 11 & 14 & 12 \\
\hline & 60 & 12 & 13 & 16 \\
\hline \multirow[t]{4}{*}{5} & 15 & 16 & 13 & 11 \\
\hline & 30 & 11 & 14 & 17 \\
\hline & 45 & 13 & 15 & 13 \\
\hline & 60 & 13 & 12 & 14 \\
\hline
\end{tabular}


Tabela 9 - Distribuição, em relação ao tempo, de adultos da espécie Callosobruchus analis (Fabr., 1775), por setor da arena, para a fonte de ${ }^{60} \mathrm{Co}$

\begin{tabular}{|c|c|c|c|c|}
\hline \multirow{2}{*}{ Repetição } & \multirow{2}{*}{$\begin{array}{l}\text { Tempo } \\
\text { (min) }\end{array}$} & \multicolumn{3}{|c|}{ Setor } \\
\hline & & 1 & 2 & 3 \\
\hline \multirow[t]{4}{*}{1} & 15 & 11 & 14 & 19 \\
\hline & 30 & 16 & 9 & 15 \\
\hline & 45 & 12 & 10 & 17 \\
\hline & 60 & 12 & 12 & 17 \\
\hline \multirow[t]{4}{*}{2} & 15 & 18 & 10 & 17 \\
\hline & 30 & 16 & 13 & 16 \\
\hline & 45 & 15 & 13 & 13 \\
\hline & 60 & 13 & 11 & 18 \\
\hline \multirow[t]{4}{*}{3} & 15 & 11 & 16 & 12 \\
\hline & 30 & 11 & 14 & 12 \\
\hline & 45 & 11 & 15 & 9 \\
\hline & 60 & 11 & 14 & 8 \\
\hline \multirow[t]{4}{*}{4} & 15 & 8 & 10 & 12 \\
\hline & 30 & 7 & 11 & 20 \\
\hline & 45 & 5 & 14 & 16 \\
\hline & 60 & 6 & 15 & 16 \\
\hline \multirow[t]{4}{*}{5} & 15 & 14 & 12 & 15 \\
\hline & 30 & 5 & 20 & 10 \\
\hline & 45 & 7 & 15 & 16 \\
\hline & 60 & 11 & 11 & 15 \\
\hline
\end{tabular}


Tabela 10 - Distribuição, em relação ao tempo, de adul tos da espécie callo sobruchus analis (Fabr., 1775), por setor da arena, na ausência de fonte radioativa (test.)

\begin{tabular}{|c|c|c|c|c|}
\hline \multirow{2}{*}{ Repetição } & \multirow{2}{*}{$\begin{array}{l}\text { Tempo } \\
\text { (min) }\end{array}$} & \multicolumn{3}{|c|}{ Setor } \\
\hline & & 1 & 2 & 3 \\
\hline \multirow[t]{4}{*}{1} & 15 & 9 & 12 & 15 \\
\hline & 30 & 8 & 13 & 13 \\
\hline & 45 & 11 & 10 & 14 \\
\hline & 60 & 11 & 10 & 16 \\
\hline \multirow[t]{4}{*}{2} & 15 & 6 & 9 & 10 \\
\hline & 30 & 9 & 9 & 8 \\
\hline & 45 & 7 & 8 & 13 \\
\hline & 60 & 4 & 11 & 13 \\
\hline \multirow[t]{4}{*}{3} & 15 & 9 & 8 & 21 \\
\hline & 30 & 10 & 8 & 18 \\
\hline & 45 & 10 & 7 & 14 \\
\hline & 60 & 14 & 8 & 15 \\
\hline \multirow[t]{4}{*}{4} & 15 & 6 & 8 & 12 \\
\hline & 30 & 9 & 12 & 14 \\
\hline & 45 & 10 & 9 & 16 \\
\hline & 60 & 8 & 9 & 16 \\
\hline \multirow[t]{4}{*}{5} & 15 & 10 & 15 & 15 \\
\hline & 30 & 8 & 14 & 17 \\
\hline & 45 & 13 & 12 & 14 \\
\hline & 60 & 11 & 12 & 19 \\
\hline
\end{tabular}


Tabela 11 - Distribuição, em relação ao tempo, de adultos da espécie Sitophilus oryzae (L., 1763), por setor da arena, para a fonte de ${ }^{241} \mathrm{Am}$

\begin{tabular}{|c|c|c|c|c|}
\hline \multirow{2}{*}{ Repetição } & \multirow{2}{*}{$\begin{array}{l}\text { Tempo } \\
\text { (min) }\end{array}$} & \multicolumn{3}{|c|}{ Setor } \\
\hline & & 1 & 2 & 3 \\
\hline \multirow[t]{4}{*}{1} & 15 & 10 & 17 & 20 \\
\hline & 30 & 10 & 17 & 18 \\
\hline & 45 & 8 & 20 & 19 \\
\hline & 60 & 12 & 16 & 20 \\
\hline \multirow[t]{4}{*}{2} & 15 & 11. & 13 & 23 \\
\hline & 30 & 10 & 15 & 18 \\
\hline & 45 & 9 & 15 & 21 \\
\hline & 60 & 11 & 17 & 16 \\
\hline \multirow[t]{4}{*}{3} & 15 & 14 & 13 & 21 \\
\hline & 30 & 14 & 11 & 23 \\
\hline & 45 & 14 & 20 & 16 \\
\hline & 60 & 14 & 11 & 16 \\
\hline \multirow[t]{4}{*}{4} & 15 & 8 & 23 & 10 \\
\hline & 30 & 8 & 15 & 20 \\
\hline & 45 & 12 & 12 & 17 \\
\hline & 60 & 7 & 21 & 12 \\
\hline \multirow[t]{4}{*}{5} & 15 & 14 & 16 & 16 \\
\hline & 30 & 9 & 18 & 22 \\
\hline & 45 & 10 & 14 & 21 \\
\hline & 60 & 15 & 10 & 20 \\
\hline
\end{tabular}


Tabela 12 - Distribuição, em relação ao tempo, de adultos da espécie Sitophilus oryzae (L., 1763), por setor da arena, para a fonte de ${ }^{6 a}{ }^{a} \mathrm{O}$

\begin{tabular}{|c|c|c|c|c|}
\hline \multirow{2}{*}{ Repetição } & \multirow{2}{*}{$\begin{array}{l}\text { Tempo } \\
\text { (min) }\end{array}$} & \multicolumn{3}{|c|}{ Setor } \\
\hline & & 1 & 2 & 3 \\
\hline \multirow[t]{4}{*}{1} & 15 & 15 & 15 & 20 \\
\hline & 30 & 13 & 22 & 13 \\
\hline & 45 & 11 & 23 & 14 \\
\hline & 60 & 15 & 18 & 12 \\
\hline \multirow[t]{4}{*}{2} & 15 & 10 & 20 & 19 \\
\hline & 30 & 20 & 19 & 9 \\
\hline & 45 & 21 & 14 & 12 \\
\hline & 60 & 13 & 21 & 15 \\
\hline \multirow[t]{4}{*}{3} & 15 & 13 & 18 & 16 \\
\hline & 30 & 16 & 14 & 10 \\
\hline & 45 & 9 & 12 & 22 \\
\hline & 60 & 17 & 18 & 8 \\
\hline \multirow[t]{4}{*}{4} & 15 & 9 & 15 & 18 \\
\hline & 30 & 12 & 16 & 15 \\
\hline & 45 & 14 & 11 & 23 \\
\hline & 60 & 17 & 9 & 18 \\
\hline \multirow[t]{4}{*}{5} & 15 & 5 & 19 & 18 \\
\hline & 30 & 8 & 21 & 18 \\
\hline & 45 & 16 & 13 & 14 \\
\hline & 60 & 9 & 15 & 16 \\
\hline
\end{tabular}


Tabela 13 - Distribuição, em relação ao tempo, de adul tos da espécie Sitophilus oryzae. (L., 1763), por setor da arena, na ausência de fonte radioativa

\begin{tabular}{|c|c|c|c|c|}
\hline \multirow{2}{*}{ Repetição } & \multirow{2}{*}{$\begin{array}{l}\text { Tempo } \\
(\min )\end{array}$} & \multicolumn{3}{|c|}{ Setor } \\
\hline & & 1 & 2 & 3 \\
\hline \multirow[t]{4}{*}{1} & 15 & 9 & 13 & 25 \\
\hline & 30 & 4 & 22 & 19 \\
\hline & 45 & 8 & 21 & 17 \\
\hline & 60 & 12 & 21 & 15 \\
\hline \multirow[t]{4}{*}{2} & 15 & 9 & 15 & 20 \\
\hline & 30 & 14 & 16 & 15 \\
\hline & 45 & 10 & 19 & 19 \\
\hline & 60 & 10 & 11 & 23 \\
\hline \multirow[t]{4}{*}{3} & 15 & 15 & 17 & 12 \\
\hline & 30 & 14 & 13 & 17 \\
\hline & 45 & 9 & 14 & 23 \\
\hline & 60 & 16 & 17 & 12 \\
\hline \multirow[t]{4}{*}{4} & 15 & 17 & 16 & 14 \\
\hline & 30 & 14 & 17 & 16 \\
\hline & 45 & 14 & 17 & 15 \\
\hline & 60 & 16 & 15 & 16 \\
\hline \multirow[t]{4}{*}{5} & 15 & 7 & 21 & 17 \\
\hline & 30 & 14 & 17 & 15 \\
\hline & 45 & 12 & 17 & 17 \\
\hline & 60 & 17 & 14 & 13 \\
\hline
\end{tabular}


Tabela 14 - Distribuição, em relação ao tempo, de adultos da espécie Ephes tia cautella (Waiker, 1864), por setor da arena, para a fonte de ${ }^{241} \mathrm{Am}$

\begin{tabular}{|c|c|c|c|c|}
\hline \multirow{2}{*}{ Repetição } & \multirow{2}{*}{$\begin{array}{l}\text { Tempo } \\
\text { (min) }\end{array}$} & \multicolumn{3}{|c|}{ Setor } \\
\hline & & 1 & 2 & 3 \\
\hline \multirow[t]{4}{*}{1} & 15 & 3 & 21 & 20 \\
\hline & 30 & 3 & 13 & 26 \\
\hline & 45 & 2 & 13 & 27 \\
\hline & 60 & 4 & 11 & 24 \\
\hline \multirow[t]{4}{*}{2} & 15 & 6 & 26 & 8 \\
\hline & 30 & 10 & 26 & 7 \\
\hline & 45 & 8 & 18 & 12 \\
\hline & 60 & 7 & 19 & 10 \\
\hline \multirow[t]{4}{*}{3} & 15 & 2 & 24 & 11 \\
\hline & 30 & 5 & 20 & 13 \\
\hline & 45 & 4 & 16 & 15 \\
\hline & 60 & 4 & 14 & 19 \\
\hline \multirow[t]{4}{*}{4} & 15 & 7 & 11 & 18 \\
\hline & 30 & 6 & 7 & 20 \\
\hline & 45 & 6 & 6 & 19 \\
\hline & 60 & 8 & 6 & 18 \\
\hline \multirow[t]{5}{*}{5} & 15 & 7 & 11 & 17 \\
\hline & 30 & 7 & 10 & 15 \\
\hline & 45 & 6 & 10 & 17 \\
\hline & 60 & 6 & 6 & 19 \\
\hline & & & & \\
\hline
\end{tabular}


Tabela 15 - Distribuição, em relação ao tempo, de adultos da espécie Ephes tia cautella (Walker, 1864), por setor da arena, para a fonte de ${ }^{60} \mathrm{Co}$

\begin{tabular}{|c|c|c|c|c|}
\hline \multirow{2}{*}{ Repetição } & \multirow{2}{*}{$\begin{array}{l}\text { Tempo } \\
\text { (min) }\end{array}$} & \multicolumn{3}{|c|}{ Setor } \\
\hline & & 1 & 2 & 3 \\
\hline \multirow[t]{4}{*}{1} & 15 & 0 & 45 & 0 \\
\hline & 30 & 8 & 29 & 6 \\
\hline & 45 & 11 & 25 & 7 \\
\hline & 60 & 12 & 22 & 8 \\
\hline \multirow[t]{4}{*}{2} & 15 & 7 & 13 & 12 \\
\hline & 30 & 10 & 13 & 12 \\
\hline & 45 & 8 & 11 & 15 \\
\hline & 60 & 7 & 13 & 15 \\
\hline \multirow[t]{4}{*}{3} & 15 & 8 & 16 & 13 \\
\hline & 30 & 4 & 17 & 14 \\
\hline & 45 & 5 & 16 & 12 \\
\hline & 60 & 3 & 24 & 11 \\
\hline \multirow[t]{4}{*}{4} & 15 & 10 & 20 & 9 \\
\hline & 30 & 6 & 12 & 14 \\
\hline & 45 & 5 & 13 & 17 \\
\hline & 60 & 5 & 13 & 14 \\
\hline \multirow[t]{4}{*}{5} & 15 & 5 & 32 & 8 \\
\hline & 30 & 7 & 26 & 11 \\
\hline & 45 & 7 & 23 & 12 \\
\hline & 60 & 7 & 22 & 12 \\
\hline
\end{tabular}


Tabela 16 - Distribuição, em relação ao tempo, de adultos da espécie Ephes tia cautella (Walker, 1864), por setor da arena, na ausência de fonte radioativa (test.)

\begin{tabular}{|c|c|c|c|c|}
\hline \multirow{2}{*}{ Repetição } & \multirow{2}{*}{$\begin{array}{l}\text { Tempo } \\
(\min )\end{array}$} & \multicolumn{3}{|c|}{ Setor } \\
\hline & & 1 & 2 & 3 \\
\hline \multirow[t]{4}{*}{1} & 15 & 9 & 20 & 9 \\
\hline & 30 & 4 & 22 & 12 \\
\hline & 45 & 7 & 18 & 13 \\
\hline & 60 & 12 & 12 & 17 \\
\hline \multirow[t]{3}{*}{2} & 15 & 3 & 26 & 16 \\
\hline & 30 & 4 & 19 & 22 \\
\hline & 45 & 8 & 19 & 15 \\
\hline & 60 & 5 & 23 & 15 \\
\hline \multirow[t]{4}{*}{3} & 15 & 8 & 22 & 13 \\
\hline & 30 & 8 & 19 & 17 \\
\hline & 45 & 8 & 19 & 17 \\
\hline & 60 & 9 & 19 & 18 \\
\hline \multirow[t]{4}{*}{4} & 15 & 1 & 13 & 25 \\
\hline & 30 & 4 & 14 & 20 \\
\hline & 45 & 5 & 10 & 21 \\
\hline & 60 & 5 & 10 & 21 \\
\hline \multirow[t]{4}{*}{5} & 15 & 10 & 27 & 11 \\
\hline & 30 & 15 & 17 & 13 \\
\hline & 45 & 12 & 16 & 14 \\
\hline & 60 & 17 & 16 & 12 \\
\hline
\end{tabular}


Tabela 17 - Distribuição, em relação ao tempo, de adultos da espécie Tribó lium castaneum (Herbst, 1797), por setor da arena, para a fonte de ${ }^{241} \mathrm{Am}$

\begin{tabular}{|c|c|c|c|c|}
\hline \multirow{2}{*}{ Repeti ção } & \multirow{2}{*}{$\begin{array}{l}\text { Tempo } \\
\text { (min) }\end{array}$} & \multicolumn{3}{|c|}{ Setor } \\
\hline & & 1 & 2 & 3 \\
\hline \multirow[t]{4}{*}{1} & 15 & $1 \cdot 7$ & 15 & 11 \\
\hline & 30 & 19 & 15 & 9 \\
\hline & 45 & 20 & .14 & 10 \\
\hline & 60 & 21 & 12 & 12 \\
\hline \multirow[t]{4}{*}{2} & 15 & 15 & 33 & 2 \\
\hline & 30 & 9 & 26 & 6 \\
\hline & 45 & 16 & 29 & 4 \\
\hline & $\cdot 60$ & 13 & 32 & 2 \\
\hline \multirow[t]{4}{*}{3} & 15 & 11 & 20 & 23 \\
\hline & 30 & 21 & 13 & 15 \\
\hline & 45 & 18 & 9 & 12 \\
\hline & 60 & 18 & 15 & 14 \\
\hline \multirow[t]{4}{*}{4} & 15 & 11 & 18 & 19 \\
\hline & 30 & 13 & 18 & 14 \\
\hline & 45 & 11 & 18 & 17 \\
\hline & 60 & 7 & 23 & 17 \\
\hline \multirow[t]{4}{*}{5} & 15 & 13 & 14 & 20 \\
\hline & 30 & 16 & 8 & 20 \\
\hline & 45 & 16 & 9 & 17 \\
\hline & 60 & 8 & 14 & 19 \\
\hline
\end{tabular}


Tabela 18 - Distribuição, em relação ao tempo, de adultos da espécie Tribo lium castaneum (Herbst, 1797), por setor da arena, para a fonte de ${ }^{60} \mathrm{Co}$

\begin{tabular}{|c|c|c|c|c|}
\hline \multirow{2}{*}{ Repetição } & \multirow{2}{*}{$\begin{array}{l}\text { Tempo } \\
\text { (min) }\end{array}$} & \multicolumn{3}{|c|}{ Setor } \\
\hline & & 1 & 2 & 3 \\
\hline \multirow[t]{4}{*}{1} & 15 & 14 & 19 & 11 \\
\hline & 30 & 25 & 13 & 6 \\
\hline & 45 & 26 & 9 & 8 \\
\hline & 60 & 31 & 7 & 4 \\
\hline \multirow[t]{4}{*}{2} & 15 & 12 & 20 & 11 \\
\hline & 30 & 17 & 13 & 14 \\
\hline & 45 & 15 & 18 & 12 \\
\hline & 60 & 20 & 18 & 9 \\
\hline \multirow[t]{4}{*}{3} & 15 & 16 & 13 & 16 \\
\hline & 30 & 12 & 15 & 17 \\
\hline & 45 & 18 & 10 & 14 \\
\hline & 60 & 15 & 11 & 17 \\
\hline \multirow[t]{4}{*}{4} & 15 & 11 & 16 & 13 \\
\hline & 30 & 9 & 14 & 16 \\
\hline & 45 & 9 & 8 & 24 \\
\hline & 60 & 13 & 10 & 23 \\
\hline \multirow[t]{4}{*}{5} & 15 & 14 & 13 & 16 \\
\hline & 30 & 13 & 15 & 14 \\
\hline & 45 & 10 & 16 & 20 \\
\hline & 60 & 11 & 18 & 13 \\
\hline
\end{tabular}


Tabela 19 - Distribuição, em relação ao tempo, de adultos da espécie Tríbo lium castaneum (Herbst, 1979), por setor da arena, na ausência de fonte radioativa (test.)

\begin{tabular}{|c|c|c|c|c|}
\hline \multirow{2}{*}{ Repetição } & \multirow{2}{*}{$\begin{array}{l}\text { Tempo } \\
\text { (min) }\end{array}$} & \multicolumn{3}{|c|}{ Setor } \\
\hline & & 1 & 2 & 3 \\
\hline \multirow[t]{4}{*}{1} & 15 & 20 & 15 & 9 \\
\hline & 30 & 12 & 9 & 15 \\
\hline & 45 & 16 & 10 & 10 \\
\hline & 60 & 13 & 11 & 18 \\
\hline \multirow[t]{4}{*}{2} & 15 & 8 & 17 & 20 \\
\hline & 30 & 10 & 13 & 21 \\
\hline & 45 & 3 & 23 & 21 \\
\hline & 60 & 5 & 22 & 18 \\
\hline \multirow[t]{4}{*}{3} & 15 & 11 & 15 & 19 \\
\hline & 30 & 15 & -15 & 8 \\
\hline & 45 & 11 & 23 & 9 \\
\hline & 60 & 8 & 24 & 6 \\
\hline \multirow[t]{4}{*}{4} & 15 & 17 & 14 & 13 \\
\hline & 30 & 8 & 12 & 24 \\
\hline & 45 & 12 & 13 & 15 \\
\hline & 60 & 14 & 14 & 13 \\
\hline \multirow[t]{4}{*}{5} & 15 & 13 & 20 & 14 \\
\hline & 30 & 16 & 15 & 16 \\
\hline & 45 & 17 & 17 & 19 \\
\hline & 60 & 9 & 24 & 16 \\
\hline
\end{tabular}


Tabela 20 - Distribuição, em relação ao tempo, de adultos da espécie Atta bisphaerica Forel, 1908, por setor da arena, para a fonte de ${ }^{241} \mathrm{Am}$

\begin{tabular}{|c|c|c|c|c|}
\hline \multirow{2}{*}{ Repetição } & \multirow{2}{*}{$\begin{array}{l}\text { Tempo } \\
\text { (min) }\end{array}$} & \multicolumn{3}{|c|}{ Setor } \\
\hline & & 1 & 2 & 3 \\
\hline \multirow[t]{4}{*}{1} & 15 & 9 & 45 & 2 \\
\hline & 30 & 13 & 38 & 10 \\
\hline & 45 & 11 & 29 & 18 \\
\hline & 60 & 10 & 24 & 24 \\
\hline \multirow[t]{4}{*}{2} & 15 & 7 & 37 & 12 \\
\hline & 30 & 9 & 33 & 12 \\
\hline & 45 & 6 & 35 & 13 \\
\hline & 60 & 11 & 33 & 11 \\
\hline \multirow[t]{4}{*}{3} & 15 & 8 & 37 & 8 \\
\hline & 30 & 4 & 36 & 11 \\
\hline & 45 & 9 & 30 & 13 \\
\hline & 60 & 13 & 38 & 12 \\
\hline \multirow[t]{4}{*}{4} & 15 & 31 & 22 & 2 \\
\hline & 30 & 9 & 38 & 4 \\
\hline & 45 & 7 & 33 & 11 \\
\hline & 60 & 10 & 31 & 13 \\
\hline \multirow[t]{4}{*}{5} & 15 & 2 & 45 & 0 \\
\hline & 30 & 8 & 37 & 3 \\
\hline & 45 & 12 & 23 & 13 \\
\hline & 60 & 7 & 23 & 17 \\
\hline
\end{tabular}


Tabela 21 - Distribuição, em relação ao tempo, de adultos da espécie Atta bisphaerica Forel, 1908, por setor da arena, para a fonte de ${ }^{60} \mathrm{Co}$

\begin{tabular}{|c|c|c|c|c|}
\hline \multirow{2}{*}{ Repetição } & \multirow{2}{*}{$\begin{array}{l}\text { Tempo } \\
\text { (min) }\end{array}$} & \multicolumn{3}{|c|}{ Setor } \\
\hline & & 1 & 2 & 3 \\
\hline \multirow[t]{4}{*}{1} & 15 & 8 & 30 & 10 \\
\hline & 30 & 13 & 29 & 5 \\
\hline & 45 & 16 & 22 & 8 \\
\hline & 60 & 19 & 21 & 6 \\
\hline \multirow[t]{4}{*}{2} & 15 & 10 & 31 & 6 \\
\hline & 30 & 13 & 26 & 9 \\
\hline & 45 & 11 & 29 & 6 \\
\hline & 60 & 9 & 33 & 7 \\
\hline \multirow[t]{4}{*}{3} & 15 & 4 & 42 & 4 \\
\hline & 30 & 5 & 41 & 3 \\
\hline & 45 & 13 & 31 & 5 \\
\hline & 60 & 11 & 29 & 10 \\
\hline \multirow[t]{4}{*}{4} & 15 & 6 & 41 & 3 \\
\hline & 30 & 4 & 40 & 6 \\
\hline & 45 & 11 & 31 & 6 \\
\hline & 60 & 12 & 22 & 16 \\
\hline \multirow[t]{3}{*}{5} & 15 & 11 & 38 & 1 \\
\hline & 30 & 11 & 36 & 3 \\
\hline & 45 & 14 & 31 & 5 \\
\hline & 60 & 12 & 27 & 10 \\
\hline
\end{tabular}


Tabela 22 - Distribuição, em relação ao tempo, de adultos da espécie Atta bisphaerica Forel, 1908, por setor da arena, na ausência de fonte radioativa (test.)

\begin{tabular}{|c|c|c|c|c|}
\hline \multirow{2}{*}{ Repetição } & \multirow{2}{*}{$\begin{array}{l}\text { Tempo } \\
\text { (min) }\end{array}$} & \multicolumn{3}{|c|}{ Setor } \\
\hline & & 1 & 2 & 3 \\
\hline \multirow[t]{4}{*}{1} & 15 & 5 & 38 & 7 \\
\hline & 30 & 9 & 37. & 4 \\
\hline & 45 & 4 & 39 & 7 \\
\hline & 60 & 7 & 25 & 17 \\
\hline \multirow[t]{4}{*}{2} & 15 & 9 & 30 & 13 \\
\hline & 30 & 11 & 26 & 16 \\
\hline & 45 & 9 & 21 & 22 \\
\hline & 60 & 15 & 21 & 16 \\
\hline \multirow[t]{4}{*}{3} & 15 & 7 & 37 & 4 \\
\hline & 30 & 10 & 29 & 13 \\
\hline & 45 & 10 & 16 & 23 \\
\hline & 60 & 9 & 18 & 20 \\
\hline \multirow[t]{4}{*}{4} & 15 & 17 & 33 & 3 \\
\hline & 30 & 17 & 25 & 11 \\
\hline & 45 & 10 & 19 & 23 \\
\hline & 60 & 13 & 20 & 21 \\
\hline \multirow[t]{4}{*}{5} & 15 & 9 & 39 & 2 \\
\hline & 30 & 6 & 38 & 6 \\
\hline & 45 & 12 & 30 & 8 \\
\hline & 60 & 6 & 36 & 9 \\
\hline
\end{tabular}


Tabela 23 - Distribuição, em relação ao tempo, de adultos da espécie Camponotus rufipes (Fabr., 1.775), por setor da arena, para a fonte de ${ }^{241} \mathrm{Am}$

\begin{tabular}{|c|c|c|c|c|}
\hline \multirow{2}{*}{ Repetição } & \multirow{2}{*}{$\begin{array}{l}\text { Tempo } \\
\text { (min) }\end{array}$} & \multicolumn{3}{|c|}{ Setor } \\
\hline & & 1 & 2 & 3 \\
\hline \multirow[t]{4}{*}{1} & 15 & 13 & 33 & 4 \\
\hline & 30 & 15 & 32 & 4 \\
\hline & 45 & 27 & 23 & 1 \\
\hline & 60 & 17 & 24 & 9 \\
\hline \multirow[t]{4}{*}{2} & 15 & 12 & 32 & 6 \\
\hline & 30 & 15 & 32 & 3 \\
\hline & 45 & 13 & 35 & 2 \\
\hline & 60 & 14 & 28 & 8 \\
\hline \multirow[t]{4}{*}{3} & 15 & 17 & 35 & 1 \\
\hline & 30 & 12 & 31 & 3 \\
\hline & 45 & 15 & 33 & 2 \\
\hline & 60 & 8 & 40 & 2 \\
\hline \multirow[t]{4}{*}{4} & 15 & 5 & 44 & 0 \\
\hline & 30 & 8 & 41 & 1 \\
\hline & 45 & 5 & 41 & 4 \\
\hline & 60 & 11 & 38 & 1 \\
\hline \multirow[t]{4}{*}{5} & 15 & 3 & 47 & 0 \\
\hline & 30 & 6 & 42 & 2 \\
\hline & 45 & 10 & 39 & 1 \\
\hline & 60 & 7 & 40 & 3 \\
\hline
\end{tabular}


Tabela 24 - Distribuição, em relação ao tempo, de adultos da espécie Camponotus rufipes (Fabr., 1775), por setor da arena, para a fon te de ${ }^{60} \mathrm{Co}$

\begin{tabular}{|c|c|c|c|c|}
\hline \multirow{2}{*}{ Repetição } & \multirow{2}{*}{$\begin{array}{l}\text { Tempo } \\
(\min )\end{array}$} & \multicolumn{3}{|c|}{ Setor } \\
\hline & & 1 & 2 & 3 \\
\hline \multirow[t]{4}{*}{1} & 15 & 0 & 50 & 0 \\
\hline & 30 & 0 & 49 & 1 \\
\hline & 45 & 0 & 50 & 0 \\
\hline & 60 & 0 & 49 & 1 \\
\hline \multirow[t]{4}{*}{2} & 15 & 1 & 48 & 1 \\
\hline & 30 & 4 & 44 & 2 \\
\hline & 45 & 2 & 44 & 4 \\
\hline & 60 & 3 & 46 & 1 \\
\hline \multirow[t]{4}{*}{3} & 15 & 12 & 34 & 3 \\
\hline & 30 & 16 & 35 & 1 \\
\hline & 45 & 16 & 33 & 1 \\
\hline & 60 & 17 & 30 & 3 \\
\hline \multirow[t]{4}{*}{4} & 15 & 13 & 33 & 2 \\
\hline & 30 & 13 & 37 & 1 \\
\hline & 45 & 15 & 34 & 1 \\
\hline & 60 & 17 & 32 & 1 \\
\hline \multirow[t]{4}{*}{5} & 15 & 10 & 38 & 2 \\
\hline & 30 & 11 & 37 & 2 \\
\hline & 45 & 9 & 39 & 2 \\
\hline & 60 & 10 & 39 & 1 \\
\hline
\end{tabular}


Tabela 25 - Distribuição, em relação ao tempo, de adultos da espécie camponotus rufipes (Fabr., 1775), por setor da arena, na ausēncia de fonte radioativa (test.)

\begin{tabular}{|c|c|c|c|c|}
\hline \multirow{2}{*}{ Repetição } & \multirow{2}{*}{$\begin{array}{l}\text { Tempo } \\
(\min )\end{array}$} & \multicolumn{3}{|c|}{ Setor } \\
\hline & & 1 & 2 & 3 \\
\hline \multirow[t]{4}{*}{1} & 15 & 7 & 36 & 6 \\
\hline & 30 & 5 & 40 & 4 \\
\hline & 45 & 4 & 31 & 15 \\
\hline & 60 & 4 & 36 & 11 \\
\hline \multirow[t]{4}{*}{2} & 15 & 14 & 33 & 3 \\
\hline & 30 & 12 & 37 & 1 \\
\hline & 45 & 15 & 29 & 6 \\
\hline & 60 & 9 & 38 & 3 \\
\hline \multirow[t]{4}{*}{3} & 15 & 5 & 40 & 5 \\
\hline & 30 & 6 & 39 & 5 \\
\hline & 45 & 6 & 37 & 7 \\
\hline & 60 & 8 & 38 & 4 \\
\hline \multirow[t]{4}{*}{4} & 15 & 6 & 34 & 10 \\
\hline & 30 & 10 & 34 & 6 \\
\hline & 45 & 11 & 32 & 7 \\
\hline & 60 & 18 & 25 & 7 \\
\hline \multirow[t]{4}{*}{5} & 15 & 3 & 45 & 2 \\
\hline & 30 & 8 & 39 & 3 \\
\hline & 45 & 6 & 40 & 4 \\
\hline & 60 & 7 & 39 & 4 \\
\hline
\end{tabular}


Tabela 26 - Distribuição, em relação ao tempo, de adultos da espécie Ceratitis capitata (Wied., 1824), por setor da arena, para a fonte de ${ }^{241} \mathrm{Am}$

\begin{tabular}{|c|c|c|c|c|}
\hline \multirow{2}{*}{ Repetição } & \multirow{2}{*}{$\begin{array}{l}\text { Tempo } \\
\text { (min) }\end{array}$} & \multicolumn{3}{|c|}{ Setor } \\
\hline & & 7 & 2 & 3 \\
\hline \multirow[t]{4}{*}{1} & 15 & 5 & 24 & 7 \\
\hline & 30 & 11 & 19 & 7 \\
\hline & 45 & 10 & 16 & 7 \\
\hline & 60 & 7 & 13 & 10 \\
\hline \multirow[t]{4}{*}{2} & 15 & 14 & 33 & 0 \\
\hline & 30 & 16 & 21 & 5 \\
\hline & 45 & 13 & 18 & 8 \\
\hline & 60 & 13 & 14 & 11 \\
\hline \multirow[t]{4}{*}{3} & 15 & 13 & 32 & 4 \\
\hline & 30 & 12 & 28 & 7 \\
\hline & 45 & 13 & 26 & 7 \\
\hline & 60 & 14 & 26 & 7 \\
\hline \multirow[t]{4}{*}{4} & 15 & 6 & 39 & 5 \\
\hline & 30 & 9 & 25 & 13 \\
\hline & 45 & 6 & 21 & 12 \\
\hline & 60 & 6 & 23 & 11 \\
\hline \multirow[t]{4}{*}{5} & 15 & 9 & 22 & 4 \\
\hline & 30 & 5 & 18 & 5 \\
\hline & 45 & 5 & 15 & 6 \\
\hline & 60 & 5 & 15 & 5 \\
\hline
\end{tabular}


Tabela 27 - Distribuição, em relação ao tempo, de adultos da espécie Ceratitis capitata (Wied., 1824), por setor da arena, para a fonte de ${ }^{60} \mathrm{Co}$

\begin{tabular}{|c|c|c|c|c|}
\hline \multirow{2}{*}{ Repetição } & \multirow{2}{*}{$\begin{array}{l}\text { Tempo } \\
\text { (min) }\end{array}$} & \multicolumn{3}{|c|}{ Setor } \\
\hline & & 1 & 2 & 3 \\
\hline \multirow[t]{4}{*}{1} & 15 & 9 & 38 & 1 \\
\hline & 30 & 12 & 33 & 3 \\
\hline & 45 & 12 & 32 & 4 \\
\hline & 60 & 14 & 29 & 3 \\
\hline \multirow[t]{4}{*}{2} & 15 & 5 & 42 & 3 \\
\hline & 30 & 7 & 40 & 2 \\
\hline & 45 & 10 & 33 & 5 \\
\hline & 60 & 12 & 30 & 6 \\
\hline \multirow[t]{4}{*}{3} & 15 & 3 & 39 & 6 \\
\hline & 30 & 3 & 32 & 8 \\
\hline & 45 & 7 & 22 & 11 \\
\hline & 60 & 7 & 21 & 14 \\
\hline \multirow[t]{4}{*}{4} & 15 & 5 & 43 & 2 \\
\hline & 30 & 8 & 30 & 11 \\
\hline & 45 & 7 & 22 & 18 \\
\hline & 60 & 8 & 23 & 12 \\
\hline \multirow[t]{4}{*}{5} & 15 & 19 & 29 & 1 \\
\hline & 30 & 18 & 20 & 6 \\
\hline & 45 & 12 & 20 & 6 \\
\hline & 60 & 11 & 21 & 6 \\
\hline
\end{tabular}


Tabela 28 - Distribuição, em relação ao tempo, de adul tos da espécie ceratitis capitata (Wied., 1824), por setor da arena, na ausēncia de fonte radioativa (test.)

\begin{tabular}{|c|c|c|c|c|}
\hline \multirow{2}{*}{ Repetição } & \multirow{2}{*}{$\begin{array}{l}\text { Tempo } \\
\text { (min) }\end{array}$} & \multicolumn{3}{|c|}{ Setor } \\
\hline & & 1 & 2 & 3 \\
\hline \multirow[t]{4}{*}{1} & 15 & 11 & 35 & 2 \\
\hline & 30 & 10 & 24 & 9 \\
\hline & 45 & 9 & 18 & 9 \\
\hline & 60 & 9 & 23 & 7 \\
\hline \multirow[t]{4}{*}{2} & 15 & 10 & 39 & 0 \\
\hline & 30 & 14 & 24 & 5 \\
\hline & 45 & 16 & 19 & 5 \\
\hline & 60 & 11 & 22 & 7 \\
\hline \multirow[t]{4}{*}{3} & 15 & 3 & 41 & 6 \\
\hline & 30 & 9 & 31 & 9 \\
\hline & 45 & 11 & 26 & 12 \\
\hline & 60 & 12 & 25 & 12 \\
\hline \multirow[t]{4}{*}{4} & 15 & 6 & 41 & 2 \\
\hline & 30 & 6 & 33 & 5 \\
\hline & 45 & 9 & 32 & 4 \\
\hline & 60 & 8 & 30 & 7 \\
\hline \multirow[t]{4}{*}{5} & 15 & 9 & 41 & 0 \\
\hline & 30 & 11 & 28 & 6 \\
\hline & 45 & 7 & 23 & 9 \\
\hline & 60 & 7 & 22 & 9 \\
\hline
\end{tabular}




\section{ANALISE DOS RESULTADOS E DISCUSSÃO}

\subsection{Testes estatisticos utilizados}

Na análise dos resultados utilizou-se os testes estatisticos não paramétricos de Friedman e de Kruskal-Wallis.

O teste de Friedman foi usado na comparação da distribuição dos insetos nos 3 setores, $\mathrm{S}_{1}, \mathrm{~S}_{2}$ e $\mathrm{S}_{3}$, combinando-se as fontes radioativas de ${ }^{241} \mathrm{Am}$ e ${ }^{60} \mathrm{Co}$ e tratamento testemunha com os tempos de 15, 30, 45 e 60 minutos, tomando-se as 5 repetições. Cada uma das repetições foi considerada como um bloco $(n=5)$ e as contagens dos insetos nos 3 setores considerados, como observações dentro de cada bloco $\{k=3\}$.

0 mesmo teste anterior foi utilizado no confronto entre a distribuição dos insetos nos tempos de fotografação, 15, 30, 45 e 60 minutos, para as fontes de ${ }^{241} \mathrm{Am}$ e ${ }^{60}$ Co e testemunha combinadas com os setores $S_{1}, S_{2}$ e $S_{3}$, considerando-se as 5 repetições. Cada uma das 5 repetições foi considerada como sendo um bloco $(n=5)$ e a porcentagem do número total 
de insetos de cada repetição, nos 4 tempos considerados, como observações em um mesmo bloco $(k=4)$.

O teste de Kruskal-Wallis se prestou para verificar as discrepāncias na distribuição dos insetos submetidos às fontes de ${ }^{241} \mathrm{Am}$ e ${ }^{60}$ Co e ausência de fonte (testemunha) em relação às combinações entré os setores $\mathrm{S}_{1}, \mathrm{~S}_{2}$ e $\mathrm{S}_{3}$ e os tempos de 15, 30, 45 e 60 minutos. Neste caso, cada uma das 5 repetições $(n=5)$ representou 3 observações independentes $[k=3]$ da distribuição dos insetos em relação às fontes radioativas de ${ }^{241} \mathrm{Am} \mathrm{e}{ }^{60}$ Co e testemunha. Aqui também foi tomado o percentual do número total de inșetos de cada repetição, por setor da arena.

Os resultados dos testes mencionados, para as espécies estu dadas, foram condensados nas tabelas de números 29 a 55. A auséncia de dados nas tabelas foi devida a não existência de diferenças significativas entre os parámetros testados, nos níveis de probabilidade geralmente consi derados; portanto, não foi necessária a comparação múltipla entre eles.

Os limites das distribuições de $x_{r}^{2}$ do teste de Friedman e de h do teste de Kruskal-Wallis, bem como as diferenças mínimas significativas para as comparações múltiplas de ambos os testes, considerando-se di versos níveis de probabilidade, encontram-se nos apēndices 1 a 4. 
6.2. Resultados dos testes estatĩsticos e discussão para as diferentes espēcies

Tabela 29 - Valores de $X_{r}^{2}$ do teste de Friedman e comparações mūltiplas entre o número de adultos de Zabrotes subfasciatus (Boh., 1833) presentes em cada setor (S) da arena em relação aos tratamentos e tempos considerados

\begin{tabular}{|c|c|c|c|c|c|}
\hline Tratamento & Tempo (min) & $x_{r}^{2}$ & $\mathrm{~S}_{1} \times \mathrm{S}_{2}$ & $\mathrm{~S}_{1} \times \mathrm{S}_{3}$ & $S_{2} \times S_{3}$ \\
\hline \multirow[t]{4}{*}{${ }^{241} \mathrm{Am}$} & 15 & 3,26 & - & - & - \\
\hline & 30 & 0,78 & - & - & - \\
\hline & 45 & 2,80 & - & - & - \\
\hline & 60 & 7,60 & 7 & 8 & 1 \\
\hline \multirow[t]{4}{*}{${ }^{60} \mathrm{Co}$} & 15 & 2,84 & - & - & - \\
\hline & 30 & 0,74 & - & - & - \\
\hline & 45 & 6,42 & 7 & 7 & 0 \\
\hline & 60 & 0,00 & - & - & - \\
\hline \multirow[t]{4}{*}{ Test. } & 15 & 8,32 & 8 & 6 & 2 \\
\hline & 30 & 1,96 & - & - & - \\
\hline & 45 & 0,95 & - & - & - \\
\hline & 60 & 0,74 & - & - & - \\
\hline
\end{tabular}


Tabela 30 - Valores de $X_{r}^{2}$ do teste de Friedman e comparações mūltiplas entre o percentual do número total de adultos de Zabrotes subfasciatus (Boh., 1833) encontrados em cada tempo de contagem ( $t$ ) em relação aos tratamentos e setores ( $S$ ) considerados

Tratamento $s \quad x_{r} \quad t_{15} \times t_{30} \quad t_{15} \times t_{45} \quad t_{15} \times t_{60} \quad t_{30} \times t_{45} \quad t_{30} \times t_{60} \quad t_{45} \times t_{60}$

$\begin{array}{rrrrrrrrr}{ }^{241} \mathrm{Am} & 1 & 6,36 & 2 & 7 & 9 & 5 & 7 & 2 \\ & 2 & 4,96 & - & - & - & - & - & - \\ & 3 & 1,08 & - & - & - & - & - & \\ { }^{60}{ }_{\mathrm{Co}} & 1 & 9,96 & 8 & 0 & 10 & 8 & 2 & 10 \\ & 2 & 5,82 & 6 & 6 & 10 & 0 & 4 & 3 \\ & 3 & 8,28 & 2 & 11 & 5 & 9 & 3 & 6 \\ \text { Test. } & 1 & 3,24 & - & - & - & - & - & - \\ & 2 & 4,84 & - & - & - & - & - & -\end{array}$


Tabela 31 - Valores de $h$ do teste de Kruskal-Wallis e comparações mūltiplas entre os tratamentos em relação ao percentual do nūmero total de adultos de Zabrotes subfasciatus (Boh., 1833) presen tes nos setores (S), nos tempos considerados

\begin{tabular}{|c|c|c|c|c|c|}
\hline S & Tempo (min) & $h$ & ${ }^{241} \mathrm{Am} \times{ }^{60} \mathrm{Co}$ & ${ }^{241} \mathrm{Am} \times$ Test. & ${ }^{60} \mathrm{Co} \times$ Test. \\
\hline \multirow[t]{4}{*}{1} & 15 & 2,580 & - & - & - \\
\hline & 30 & 4,454 & 18 & 30 & 11 \\
\hline & 45 & 6,180 & 33 & 6 & 27 \\
\hline & 60 & 4,985 & 24 & 30 & 5 \\
\hline \multirow[t]{4}{*}{2} & 15 & 0,095 & - & - & - \\
\hline & 30 & 0,696 & - & - & - \\
\hline & 45 & 1,520 & - & - & - \\
\hline & 60 & 1,820 & - & - & - \\
\hline \multirow[t]{4}{*}{3} & 15 & 0,180 & - & - & - \\
\hline & 30 & 3,532 & 25 & 20 & 5 \\
\hline & 45 & 2,340 & - & - & - \\
\hline & 60 & 1,235 & - & - & - \\
\hline
\end{tabular}


Pelas tabelas $2,3,4$ e 29 nota-se que, decorridos 60 minutos, houve um acúmulo de insetos no setor 1 em relação ao setor 3, na presença da fonte de ${ }^{241} \mathrm{Am}$, sendo a diferença significativa ao nível de $3,9 \%$ de probabilidade. Na presença da fonte de ${ }^{6}{ }^{a}$ Co, o número de insetos não diferiu estatisticamente nos 3 setores para os 4 tempos considerados, nos níveis de probabilidade normalmente considerados. Para o tratamento testemunha, somente no tempo de 15 minutos a presença de adultos foi maior no setor 2 que no setor 1, com uma diferença significativa a 3,9\% de probabilidade.

Com base nas tabelas 2, 3, 4 e 30, para o tratamento fonte de ${ }^{241} \mathrm{Am}$, o número de indivíduos não diferiu estatisticamente em relação aos 4 tempos de contagem, para cada um dos 3 setores. Para a fonte de ${ }^{60}$ Co, os insetos estiveram em maior número no setor 3 após 45 minutos do que no tempo de 15 minutos, sendo a diferença significativa ao nível de 3,7\% de probabilidade. Na auséncia de fonte radioativa, não houve diferença estatística, nos níveis de probabilidade geralmente considerados, na distribuição dos insetos com o decorrer do tempo.

Pelas tabelas 2, 3, 4 e 31, observa-se que só existiu diferença significativa ao nível de $4,8 \%$ de probabilidade entre o número de insetos no setor 1 para o tempo de 45 minutos, considerando-se exposição às fontes de ${ }^{241} \mathrm{Am} \mathrm{e}{ }^{60} \mathrm{Co}$. Neste caso, mesmo com predominäncia de insetos expostos às radiações do ${ }^{241} \mathrm{Am}$ em relação ao ${ }^{6 a} \mathrm{Co}$, não se pode afirmar que houve aproximação, pois o tratamento fonte de ${ }^{241} \mathrm{Am}$ não diferiu estatisticamente do tratamento testemunha quanto ao número de insetos neste se tor. 
Portanto, embora tenham existido algumas diferenças signifí cativas entre os parámetros considerados nos testes estatísticos, nada se pode generalizar em relação à radioperceptividade gama dos adultos de Zabrotes subfasciatus: (Boh., 1833). 
Tabela 32 - Valores de $X_{r}^{2}$ do teste de Friedman e comparações mūitiplas entre o número de adu1tos de Acanthoscelides obtectus (Say, 1831) presentes em cada setor (S) da arena em relação aos tratamentos e tempos considerados

\begin{tabular}{|c|c|c|c|c|c|}
\hline Tratamento & Tempo (min) & $x_{r}^{2}$ & $\mathrm{~S}_{1} \times \mathrm{S}_{2}$ & $S_{1} \times S_{3}$ & $S_{2} \times S_{3}$ \\
\hline \multirow[t]{4}{*}{$241 \mathrm{Am}$} & 15 & 5,20 & 5 & 7 & 2 \\
\hline & 30 & 1,37 & - & - & - \\
\hline & 45 & 2,21 & - & - & - \\
\hline & 60 & 2,21 & - & - & - \\
\hline \multirow[t]{4}{*}{${ }^{60} \mathrm{Co}$} & 15 & 0,40 & - & - & - \\
\hline & 30 & 1,60 & - & - & - \\
\hline & 45 & 5,65 & 0 & 6 & 6 \\
\hline & 60 & 1,60 & - & - & - \\
\hline \multirow[t]{4}{*}{ Test. } & 15 & 6,00 & 3 & 8 & 4 \\
\hline & 30 & 7,44 & 2 & 8 & 6 \\
\hline & 45 & 4,00 & 3 & 6 & 3 \\
\hline & 60 & 1,20 & - & - & - \\
\hline
\end{tabular}


Tabela 33 - Valores de $X_{r}^{2}$ do teste de Friedman e comparações mūltiplas entre o percentual do número total de adultos de Acanthoscelides obtectus (Say, 1831) encontrados em cada tempo de contagem ( $t$ ) em relação aos tratamentos e setores (S) considerados

Tratamento $s \quad x_{r}^{2} \quad t_{15} \times t_{30} \quad t_{15} \times t_{45} \quad t_{15} \times t_{60} \quad t_{30} \times t_{45} \quad t_{30} \times t_{60} \quad t_{45} \times t_{60}$

\begin{tabular}{|c|c|c|}
\hline $2{ }^{41} \mathrm{Am}$ & 1 & 3,24 \\
\hline & 2 & 3,24 \\
\hline & 3 & 2,04 \\
\hline
\end{tabular}

${ }^{60}$ Co $\quad 10,60$

23,48

$3 \quad 3,37$

Test. 14,92

23,49

32,51 
Tabela 34 - Valores de $h$ do teste de Kruskal-Wallis e comparações múltiplas entre os tratamentos em relação ao percentual do número total de adultos de Acanthoscelides obtectus (Say, 1831) presentes nos setores (S), nos tempos considerados

\begin{tabular}{|c|c|c|c|c|c|}
\hline$S$ & Tempo (min) & $h$ & ${ }^{241} \mathrm{Am} \times{ }^{60} \mathrm{Co}$ & ${ }^{241} \mathrm{Am} \times$ Test. & ${ }^{60} \mathrm{Co} \times$ Test. \\
\hline \multirow[t]{4}{*}{1} & 15 & 0,720 & - & - & - \\
\hline & 30 & 0,195 & - & - & - \\
\hline & 45 & 4,155 & 28 & 10 & 18 \\
\hline & 60 & 0,020 & - & - & - \\
\hline \multirow[t]{4}{*}{2} & 15 & 1,460 & - & - & - \\
\hline & 30 & 1,839 & - & - & - \\
\hline & 45 & 1,820 & - & - & - \\
\hline & 60 & 2,240 & - & - & - \\
\hline \multirow[t]{4}{*}{3} & 15 & 2,160 & - & - & - \\
\hline & 30 & 3,860 & 23 & 2 & 25 \\
\hline & 45 & 0,540 & - & - & - \\
\hline & 60 & 2,940 & - & - & - \\
\hline
\end{tabular}


Com base nas tabelas 5, 6, 7 e 32, nos níveis de significân cia geralmente considerados, hão houve diferenças estatísticas entre o número de insetos presentes nos 3 setores, para os 4 tempos e fontes de ${ }^{241} \mathrm{Am}$ e ${ }^{60}$ Co. Na ausência de fonte radioativa (testemunha), os setores 1 e 3 diferiram estatisticamente quanto ao nümero de insetos, ao nível de 3,9\% de probabilidade, nos tempos de 15 e 30 minutos.

As diferenças não foram significativas entre o número de in setos em cada setor com o decorrer do tempo, considerando-se cada um dos 3 tratamentos individualmente (tabela 33 ).

Na comparação entre os 3 tratamentos, nenhuma diferença sig nificativa foi constatada entre a distribuição dos adultos levando-se em conta os 3 setores e os 4 tempos (tabela 34 ).

Assim, nada se pode generalizar em relação à percepção de radiações gama por Acanthoscelides btectus (Say, 1831). 
Tabela 35 - Valores de $X_{r}^{2}$ do teste de Friedman e comparações mūltiplas entre o número de adultos de Callosobruchus analis (Fabr., 1775) presentes em cada setor (S) da arena em relação aos tratamentos e tempos considerados

\begin{tabular}{|c|c|c|c|c|c|}
\hline Tra tamento & Tempo (min) & $x_{r}^{2}$ & $\mathrm{~S}_{1} \times \mathrm{S}_{2}$ & $\mathrm{~S}_{7} \times \mathrm{S}_{3}$ & $s_{2} \times S_{3}$ \\
\hline \multirow[t]{4}{*}{$241 \mathrm{Am}$} & 15 & 0,40 & - & - & - \\
\hline & 30 & 6,40 & 4 & 8 & 4 \\
\hline & 45 & 5,44 & 6 & 6 & 1 \\
\hline & 60 & 2,53 & - & - & - \\
\hline \multirow[t]{4}{*}{${ }^{60}$ Co } & 15 & 2,80 & - & - & - \\
\hline & 30 & 0,95 & - & - & - \\
\hline & 45 & 0,74 & - & - & - \\
\hline & 60 & 3,11 & - & - & - \\
\hline \multirow[t]{4}{*}{ Test. } & 15 & 7,68 & 4 & 8 & 5 \\
\hline & 30 & 2,78 & - & - & - \\
\hline & 45 & 8,40 & 3 & 6 & 9 \\
\hline & 60 & 7,60 & 1 & 8 & 7 \\
\hline
\end{tabular}


Tabela 36 - Valores de $x_{r}^{2}$ do teste de:Friedman e comparações mūltiplas entre o percentual do número total de adultos de Callosobruchus analis (Fabr., 1775) encontrados em cada tempo de contagem ( $t$ ) em relação aos tratamentos e setores (S) considerados

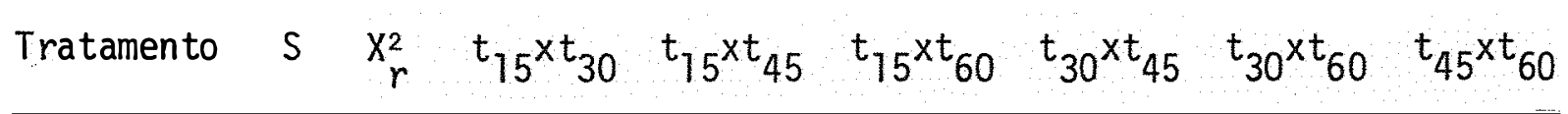

$\begin{array}{lll}24{ }^{1} \mathrm{Am} & \\ & & 3,48 \\ & 3 & 3,24 \\ & & \\ & & \\ & 1 & 0,36 \\ & 2 & 3,24 \\ & 3 & 0,36\end{array}$

Test. $16,36 \quad 3$

10

5

7

5

23,24

34,22 
Tabela 37 - Valores de $h$ do teste de Kruskal-Wallis e comparações mūltiplas entre os tratamentos em relação ao percentual do número total de adultos de Callosobruchus analis (Fabr., 1775) presen tes nos setores ( $(5)$, nos tempos considerados

\begin{tabular}{|c|c|c|c|c|c|}
\hline$S$ & Tempo (min) & $h$ & ${ }^{241} \mathrm{Am} \times{ }^{60} \mathrm{Co}$ & ${ }^{243} \mathrm{Am} \times$ Test. & ${ }^{60}$ Co $\times$ Test. \\
\hline \multirow[t]{5}{*}{1} & 15 & 5,060 & 6 & 24 & 30 \\
\hline & 30 & 0,240 & - & - & - \\
\hline & 45 & 1,298 & - & - & - \\
\hline & 60 & 2,638 & - & - & - \\
\hline & & & $a$ & & \\
\hline \multirow[t]{4}{*}{2} & 15 & 1,142 & - & - & - \\
\hline & 30 & 0,320 & - & - & - \\
\hline & 45 & 4,754 & 12 & 19 & 30 \\
\hline & 60 & 1,860 & - & - & - \\
\hline \multirow[t]{4}{*}{3} & 15 & 3,722 & 10 & 26 & 17 \\
\hline & 30 & 1,520 & - & - & - \\
\hline & 45 & 1,207 & - & - & - \\
\hline & 60 & 8,420 & 19 & 41 & 22 \\
\hline
\end{tabular}


Observando-se as tabelas $8,9,10$ e 35, nota-se que para a fonte de ${ }^{241} \mathrm{Am}$, no tempo de 30 minutos, houve diferença estatística entre - número de adultos desta espécie presentes nos setores 1 e 3, ao nível de 3,9\% de probabilidade. Neste caso, o número de insetos no setor 3 foi maior que no 1. Para a fonte de ${ }^{60} \mathrm{Co}$, nos níveis de significância normal mente utilizados, não houve diferença estatística entre a distribuição dos insetos pelos 3 setores, nos 4 tempos de contagem. Para o tratamento tes temunha, o setor 3 conteve mais insetos que o setor 1 , com uma diferença entre eles significativa a 3,9\% de probabilidade, nos tempos de 15 e 60 minutos. Ainda para este tratamento, no tempo de 45 minutos, o setor 3 apresentou maior número de indívíduos que o setor 2, sendo a diferença sig nificativa a $0,8 \%$ de probabilidade.

Para cada tratamento não houve diferença estatística, nos níveis geralmente considerados, entre o número de adultos em cada setor com o decorrer do tempo (tabela 36).

Pelas tabelas 8,10 e 37 , no confronto entre os 3 tratamentos, a ūnica diferença significativa foi entre a fonte de ${ }^{241} \mathrm{Am}$ e o tratamento testemunha, onde, no tempo de 60 minutos, houve diferença no número de insetos no setor 3 ao nível de $0,9 \%$ de probabilidade. A incidência de insetos neste setor foi maior, neste tempo, para o tratamento testemunha.

As diferenças estatísticas constatadas, entretanto, não per mitem generalizações quanto à radioperceptividade gama desta espécie. 
Tabela 38 - Valores de $x_{r}^{2}$ do teste de Friedman e comparações mūltiplas entre o número de adultos de Sitophilus onyzae (t., 1763) presen tes em cada setor $(S)$ da arena em relação aos tratamentos e tempos considerados

\begin{tabular}{|c|c|c|c|c|c|}
\hline Tratamento & Tempo (min) & $x_{r}^{2}$ & $S_{1} \times S_{2}$ & $\mathrm{~S}_{1} \times \mathrm{S}_{3}$ & $s_{2} \times s_{3}$ \\
\hline \multirow[t]{4}{*}{$241 \mathrm{Am}$} & 15 & 6,00 & 4 & 8 & 3 \\
\hline & 30 & 8,40 & 3 & 9 & 6 \\
\hline & 45 & 6,63 & 6 & 8 & 2 \\
\hline & 60 & 3,60 & 3 & 6 & 3 \\
\hline \multirow[t]{4}{*}{${ }^{6} \mathrm{a}_{\mathrm{Co}}$} & 15 & 6,42 & 7 & 6 & 0 \\
\hline & 30 & 3,26 & - & - & - \\
\hline & 45 & 0,40 & - & - & - \\
\hline & 60 & 1,60 & - & - & - \\
\hline \multirow[t]{4}{*}{ Test. } & 15 & 2,80 & - & - & - \\
\hline & 30 & 5,20 & 7 & 5 & 2 \\
\hline & 45 & 8,44 & 8 & 7 & 1 \\
\hline & 60 & 0,32 & - & - & - \\
\hline
\end{tabular}


Tabela 39 - Valores de $X_{r}^{2}$ do teste de Friedman e comparações mūltîplas entre o percentual do número total de adultos de Sitophilus oryzae (k., 1763) encontrados em cada tempo de contagem (t) em re lação aos tratamentos e setores (S) considerados

Tratamento $s \quad x_{r}^{2} \quad t_{15} \times t_{30} \quad t_{15} \times t_{45} \quad t_{15} \times t_{60} \quad t_{30} \times t_{45} \quad t_{30} \times t_{60} \quad t_{45} \times t_{60}$

\begin{tabular}{|c|c|}
\hline${ }^{24}{ }^{A m}$ & 1 \\
\hline & 2 \\
\hline & 3 \\
\hline
\end{tabular}

${ }^{60} \mathrm{Co} \quad 1 \cdot 3,96$

22,04

$3 \quad 7,08 \quad 10$

4

8

6

4

Test. $\begin{array}{cccccccc}1 & 5,40 & 1 & 3 & 6 & 2 & 7 & 9 \\ 2 & 3,73 & - & - & - & - & - \\ 3 & 0,80 & - & - & - & - & -\end{array}$


Tabela 40 - Valores de $h$ do teste de Kruskal-Wallis e comparações mūitiplas entre os tratamentos em relação ao percentual do nūmero total de adultos de Sitophilus oryzae (L., 1763) presentes nos setores $(S)$, nos tempos considerados

\begin{tabular}{|c|c|c|c|c|c|}
\hline S & Tempo (min) & $h$ & ${ }^{241} \mathrm{Am} \times{ }^{60} \mathrm{Co}$ & ${ }^{241} \mathrm{Am} \times$ Test. & ${ }^{60} \mathrm{Co} \times$ Test. \\
\hline \multirow[t]{4}{*}{1} & 15 & 0,286 & - & - & - \\
\hline & 30 & 2,540 & - & - & - \\
\hline & 45 & 2,960 & - & - & - \\
\hline & 60 & 1, 398 & - & - & - \\
\hline \multirow[t]{4}{*}{2} & 15 & 0,815 & - & - & - \\
\hline & 30 & 3,660 & 27 & 12 & 15 \\
\hline & 45 & 2,780 & - & - & - \\
\hline & 60 & 0,380 & - & - & - \\
\hline \multirow[t]{4}{*}{3} & 15 & 0,020 & - & - & - \\
\hline & 30 & 9,380 & 43 & 26 & 17 \\
\hline & 45 & 0,456 & - & - & - \\
\hline & 60 & 1,895 & - & - & - \\
\hline
\end{tabular}


Pela observação das tabelas 11, 12, 13 e 38 , verifica-se que, para esta espécie, existiram diferenças significativas entre o número de insetos nos setores 1 e 3 para os tempos de 15, 30 e 45 minutos em rela ção à fonte de ${ }^{241} \mathrm{Am}$, com predominância de insetos no setor 3 . Nos tem pos de 15 e 45 minutos, o nível de significáncia foi de $3,9 \%$ e no tempo de 30 minutos, este foi de $0,8 \%$ de probabilidade. Na presença da fonte de ${ }^{6}{ }^{a}$ Co, os 3 setores não diferiram estatisticamente entre si quanto ao nú mero de adultos, para os 4 tempos considerados. Para o tratamento testemunha, o número de insetos diferiu ao nível de $3,9 \%$ de probabilidade nos setores 1 e 2, no tempo de 45 minutos, com predomináncia dos mesmos no setor 2 .

Quanto à distribuição dos adultos em função do tempo, o nūmero destes, nos 3 setores para os 3 tratamentos, não diferiu estatisticamente nos níveis de significância geralmente considerados (tabela 39).

Embora tenha havido uma diferença significativa ao nível de 0,9\% de probabilidade entre o número de insetos no setor 3, para o tempo de 30 minutos e presença das fontes de ${ }^{241} \mathrm{Am}$ e ${ }^{60} \mathrm{Co}$, estatisticamente, nada se pode concluir em relação à diferença comportamental da espécie para estes 2 tratamentos (tabela 40).

Contudo, pode ser notada uma tendéncia dos adultos de Sitophilus oryzae (L.) se afastarem da fonte de ${ }^{241} \mathrm{Am}$, o que não ocorreu na presença da fonte de ${ }^{60}$ Co e tratamento testemunha. Tal resultado difere daquele encontrado por WIENDL e WALDER (1975) com a espécie Sitophilus zea mais Mots., onde estes insetos tenderam a evitar as radiações emitidas 
pela fonte de ${ }^{6} \mathrm{Co}$, que era $1,5 \times 10^{6}$ vezes mais ativa que a empregada neste experimento.

Portanto, para os membros do gênero Sitophilus, supõe-se que a percepção se relaciona mais com a atividade da fonte radioativa do que com a energia das radiações gama, uma vez que a fonte de ${ }^{241} \mathrm{Am}$ utiliza da era mais ativa que a de ${ }^{6}$ Co.

E como a espécie Sitophilus oryzae (L., 1763), segundo STER MER (1959), apresenta fototatismo negativo, a percepção provavelmente se dê ou através de estímulo visual direto ou de estímulo visual provocado por radiações Cerenkov, resultantes da interação das radiações gama com al gum outro componente ocular com maior índice de refração que o da água. 
Tabela 41 - Valores de $X_{r}^{2}$ do teste de Friedman e comparações mūitiplas en tre o número de adultos de Ephestia cautella (Walker, 1864) presentes em cada setor (S) da arena em relação aos tratamentos e tempos considerados

\begin{tabular}{|c|c|c|c|c|c|}
\hline Tratamento & Tempo (min) & $x_{r}^{2}$ & $S_{1} \times S_{2}$ & $s_{1} \times s_{3}$ & $\mathrm{~S}_{2} \times \mathrm{S}_{3}$ \\
\hline \multirow[t]{4}{*}{${ }^{241} \mathrm{Am}$} & 15 & 7,60 & 8 & 7 & 1 \\
\hline & 30 & 4,80 & 6 & 6 & 0 \\
\hline & 45 & 6,63 & 6 & 8 & 2 \\
\hline & 60 & 6,00 & 3 & 8 & 4 \\
\hline \multirow[t]{4}{*}{${ }^{60} \mathrm{Co}$} & 15 & 8,32 & 8 & 2 & 6 \\
\hline & 30 & 6,40 & 8 & 4 & 4 \\
\hline & 45 & 5,20 & 7 & 5 & 2 \\
\hline & 60 & 5,20 & 7 & 5 & 2 \\
\hline \multirow[t]{4}{*}{ Test. } & 15 & 7,68 & 8 & 5 & 4 \\
\hline & 30 & 5,20 & 7 & 5 & 2 \\
\hline & 45 & 8,40 & 9 & 6 & 3 \\
\hline & 60 & 2,00 & - & - & - \\
\hline
\end{tabular}


Tabela 42 - Valores de $X_{r}^{2}$ do teste de Friedman e comparações mūitiplas entre o percentual do número total de adultos de Ephestia cautel la (Walker, 1864) encontrados em cada tempo de contagem em relação aos tratamentos e setores (S) considerados

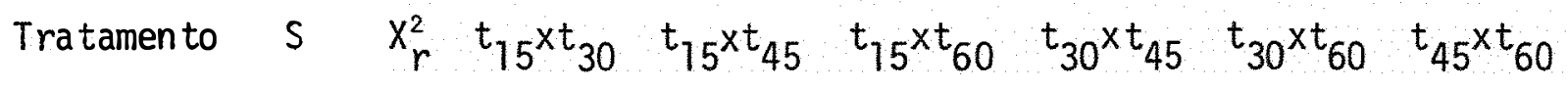

$241 \mathrm{Am} \quad 1 \quad 3,37$

213,65

$3 \quad 8,76$

3

${ }^{6 a}$ Co

1

0,12

25,20

3

6,80

4

Test.

$2 \quad 7,31 \quad 4$

$32,44=$
9

10

4

10

10

10

14

8

6

8

7

(10)

5

8

5

3

4

6

3

2

6

4

$2 \quad 6 \quad 4$


Tabela 43 - Valores de $h$ do teste de Kruskal-Wallis e comparações mūltiplas entre os tratamentos em relação ao percentual do número total de adultos de Ephestia cautella (Walker, 1864) presentes nos setores (S), nos tempos considerados

\begin{tabular}{|c|c|c|c|c|c|}
\hline$S$ & Tempo (min) & h & ${ }^{241} \mathrm{Am} \times{ }^{60} \mathrm{Co}$ & ${ }^{241} \mathrm{Am} \times$ Test. & ${ }^{60} \mathrm{Co} \times$ Test. \\
\hline \multirow[t]{4}{*}{1} & 15 & 0,860 & - & - & - \\
\hline & 30 & 1,057 & - & - & - \\
\hline & 45 & 0,665 & - & - & - \\
\hline & 60 & 1,040 & - & - & - \\
\hline \multirow[t]{4}{*}{2} & 15 & 0,720 & - & - & - \\
\hline & 30 & 1,620 & - & - & - \\
\hline & 45 & 2,855 & - & - & - \\
\hline & 60 & 4,340 & 29 & 10 & 19 \\
\hline \multirow[t]{4}{*}{3} & 15 & 2,340 & - & - & - \\
\hline & 30 & 1,680 & - & - & - \\
\hline & 45 & 2,660 & - & - & - \\
\hline & 60 & 3,620 & 26 & 19 & 7 \\
\hline
\end{tabular}


Houve diferença significativa entre o número de insetos des ta espécie presentes nos setores 1 e 2 para a fonte de ${ }^{241} \mathrm{Am}$, no tempo de 15 minutos. Nesse caso, houve maior número no setor 2 , ao nível de $3,9 \%$ de probabilidade. Também na presença das radiações gama do ${ }^{241} \mathrm{Am}$, nos. tempos de 45 e 60 minutos, existiram diferenças significativas ao nível de 3,9\% de probabilidade entre o número de adultos nos setores 1 e 3 , com pre dominância de insetos neste último. Para a fonte de ${ }^{60} \mathrm{Co}$, nos tempos de 15 e 30 minutos, o setor 2 apresentou maior número de insetos em relação ao setor 1, ao nỉvel de significância de 3,9\% de probabilidade. No trata mento testemunha, tempo de 15 minutos, houve diferença significativa ao ní vel de $3,9 \%$ de probabilidade entre o número de adultos desta espécie nos setores 1 e 2, sendo maior a sua incidência no setor 2 . No tempo de 45 minutos, observou-se o mesmo comportamento, mas com uma significáncia ao nível de $0,8 \%$ de probabilidade (tabelas 14, 15, 16 e 41 l.

Para a fonte de ${ }^{241} \mathrm{Am}$, o setor 2 apresentou maior número de insetos após 15 minutos que após 60 minutos, sendo a diferença significativa ao nível de $1,3 \%$ de probabilidade. Na presença de ${ }^{60}$ Co ou ausência de fonte radioativa, não houve diferenças estatísticas entre o número de adultos presentes em cada setor com o decorrer do tempo, nos níveis de significância geralmente considerados (tabelas 14 e 42).

No confronto entre os 3 tratamentos, também não houve diferenças significativas quanto ao número de adultos nos 3 setores e 4 tempos, como se observa na tabela 43. 
pécie de se locomoverem em direção oposta àquela onde se encontra a fonte de ${ }^{241} \mathrm{Am}$. Tal fato, contudo, não foi constatado para a fonte de ${ }^{60}$ Co ou ausência de fonte radioativa.

Aqui também a diferença entre as atividades das fontes radioativas foi mais importante na resposta comportamental do que a energia das radiações gama; o efeito Cerenkov na água ocular não foi satisfatório na explicação da detecção das radiações gama do ${ }^{241} \mathrm{Am}$, mas supõe-se que a percepção tenha ocorrido ou por estímulo visual direto, ou por produção de radiações Cerenkov, resultantes da interação das radiações gama com algum componente ocular. 
Tabela 44 - Valores de $X_{r}^{2}$ do teste de Friedman e comparações mūltiplas entre o número de adultos de Tribalium castaneum (Herbst, 1797) presentes em cada setor (S) da arena em relação aos tratamentos e tempos considerados

\begin{tabular}{|c|c|c|c|c|c|}
\hline Tratamento & Tempo (min) & $x_{r}^{2}$ & $\mathrm{~S}_{1} \times \mathrm{S}_{2}$ & $s_{1} \times s_{3}$ & $S_{2} \times S_{3}$ \\
\hline \multirow[t]{4}{*}{${ }^{241} \mathrm{Am}$} & 15 & 1,20 & - & - & - \\
\hline & 30 & 0,40 & - & - & - \\
\hline & 45 & 0,40 & - & - & - \\
\hline & 60 & 0,95 & - & - & - \\
\hline \multirow[t]{4}{*}{60 Co } & 15 & 0,32 & - & - & - \\
\hline & 30 & 0,40 & - & - & - \\
\hline & 45 & 0,40 & - & - & - \\
\hline & 60 & 0,40 & - & - & - \\
\hline \multirow[t]{4}{*}{ Test. } & 15 & 0,40 & - & - & - \\
\hline & 30 & 2,11 & - & - & - \\
\hline & 45 & 0,78 & - & - & - \\
\hline & 60 & 2,00 & - & - & - \\
\hline
\end{tabular}


Tabela 45 - Valores de $X_{r}^{2}$ do teste de Friedman e comparações mūltiplas entre o percentual do número total de adultos de Tribolium casta neum (Herbst, 1797) encontrados em cada tempo de contagem ( $t$ ) em relação aos tratamentos e setores (S) considerados.

Tratamento $s \quad x_{r}^{2} \quad t_{15^{x}} t_{30} \quad t_{15} \times t_{45} \quad t_{15} \times t_{60} \quad t_{30} \times t_{45} \quad t_{30} \times t_{60} \quad t_{45^{x t}}$

\begin{tabular}{|c|c|c|c|c|c|c|c|c|}
\hline \multirow[t]{3}{*}{${ }^{241} \mathrm{Am}$} & 1 & 5,88 & 4 & 9 & 1 & 5 & 3 & 8 \\
\hline & 2 & 4,59 & - & - & - & - & - & - \\
\hline & 3 & 0,60 & - & - & - & - & - & - \\
\hline \multirow[t]{3}{*}{${ }^{6}{ }^{0}$ Co } & 1 & 2,04 & - & - & - & - & - & - \\
\hline & 2 & 3,48 & - & - & - & - & - & - \\
\hline & 3 & 1,56 & - & - & - & - & - & - \\
\hline \multirow[t]{3}{*}{ Test. } & 1 & 3,96 & - & - & - & - & - & - \\
\hline & 2 & 8,76 & 6 & 2 & 6 & 8 & 12 & 3 \\
\hline & 3 & 4,92 & - & - & - & - & - & - \\
\hline
\end{tabular}


Tabela 46 - Valores de $h$ do teste de Kruskal-Wallis e comparações mūitiplas entre os tratamentos em relação ao percentual do número total de adultos de Tribolium castaneum (Herbst, 1797) presentes nos setores $(S)$, nos tempos considerados

\begin{tabular}{|c|c|c|c|c|c|}
\hline$S$ & Tempo (min) & $h$ & ${ }^{241} \mathrm{Am} \times{ }^{60} \mathrm{Co}$ & ${ }^{241} \mathrm{Am} \times$ Test. & ${ }^{6 a}$ Co $\times$ Test. \\
\hline \multirow[t]{4}{*}{1} & 15 & 0,667 & - & - & - \\
\hline & 30 & 0,780 & - & - & - \\
\hline & 45 & 1,620 & - & - & - \\
\hline & 60 & 3,140 & - & - & - \\
\hline \multirow[t]{4}{*}{2} & 15 & 0,140 & - & - & - \\
\hline & 30 & 0,741 & - & - & - \\
\hline & 45 & 2,000 & - & - & - \\
\hline & 60 & 3,507 & 20 & 5 & 25 \\
\hline \multirow[t]{4}{*}{3} & 15 & 0,465 & - & - & - \\
\hline & 30 & 3,260 & - & - & - \\
\hline & 45 & 0,540 & - & - & - \\
\hline & 60 & 0,420 & - & - & - \\
\hline
\end{tabular}


Pela observação das tabelas 44, 45 e 46, uma única diferença estatística, ao nível de 1,3\% de probabilidade, foi observada na ausên cia de fonte radioativa (testemunhal entre o nümero de insetos presentes no setor 2 nos tempos de 30 e 60 minutos, com maior abundância de adultos neste último (tabela 19).

Portanto, não se observaram diferenças de comportamento des ta espécie quando submetida aos 3 tratamentos, nos níveis de significancia geralmente considerados, nada podendo ser generalizado em relação à radioperceptividade gama. 
Tabela 47 - Valores de $X_{r}^{2}$ do teste de Friedman e comparações mültiplas entre o número de adultos de Atta bisphaerica Forel, 1908 presen tes em cada setor (S) da arena em relação aos tratamentos e tempos considerados

\begin{tabular}{|c|c|c|c|c|c|}
\hline Tratamento & Tempo (min) & $x_{r}^{2}$ & $S_{1} \times S_{2}$ & $s_{1} \times s_{3}$ & $\mathrm{~S}_{2} \times \mathrm{S}_{3}$ \\
\hline \multirow[t]{4}{*}{${ }^{241} \mathrm{Am}$} & 15 & 6,00 & 4 & 3 & 8 \\
\hline & 30 & 7,60 & 7 & 1 & 8 \\
\hline & 45 & 10,00 & 10 & 5 & 5 \\
\hline & 60 & 7,44 & 8 & 2 & 6 \\
\hline \multirow[t]{4}{*}{${ }^{60} \mathrm{Co}_{0}$} & 15 & 8,32 & 6 & 2 & 8 \\
\hline & 30 & 8,40 & 6 & 3 & 9 \\
\hline & 45 & 10,00 & 5 & 5 & 10 \\
\hline & 60 & 8,40 & 6 & 3 & 9 \\
\hline \multirow[t]{4}{*}{ Test. } & 15 & 7,60 & 7 & 1 & 8 \\
\hline & 30 & 7,89 & 8 . & 0 & 8 \\
\hline & 45 & 4,80 & 6 & 6 & 0 \\
\hline & 60 & 7,60 & 8 & 7 & 1 \\
\hline
\end{tabular}


Tabela 48 - Valores de $X_{r}^{2}$ do teste de Friedman e comparações mūltiplas entre 0 percentual do número total de adultos de Atta bisphaerica.Forel, 1908 encontrados em cada tempo de contagem ( $t$ ) em re lação aos tratamentos e setores (S) considerados

Tratamento $s \quad x_{r}^{2} \quad t_{15} \times t_{30} \quad t_{15} \times t_{45} \quad t_{15} \times t_{60} \quad t_{30} \times t_{45} \quad t_{30} \times t_{60} \quad t_{45} \times t_{60}$

$\begin{array}{lllllllll}{ }^{60} \text { Co } & 1 & 6,80 & 3 & 10 & 8 & 6 & 4 & 2 \\ & 2 & 8,28 & 6 & 9 & 11 & 3 & 5 & 2 \\ 3 & 4,92 & - & - & - & - & - & - \\ \text { Test. } & 1 & 1,56 & - & - & - & - & - & 0 \\ & 2 & 9,37 & 5 & 10 & 10 & 6 & 6 & 0\end{array}$


Tabela 49 - Valores de $h$ do teste de Kruskal-Nallis e comparações mūltiplas entre os tratamentos em relação ao percentual do número total de adultos de Atta bisphaerica Forel, 1908 presentes nos setores (S), nos tempos considerados

\begin{tabular}{|c|c|c|c|c|c|}
\hline $\mathrm{S}$ & Tempo $(\min )$ & $h$ & ${ }^{241} \mathrm{Am} \times{ }^{6 a} \mathrm{Co}$ & ${ }^{241} \mathrm{Am} \times$ Test. & ${ }^{60} \mathrm{Co} \times$ Test. \\
\hline \multirow[t]{4}{*}{1} & 15 & 0,320 & - & - & - \\
\hline & 30 & 1,520 & - & - & - \\
\hline & 45 & 6,695 & 34 & 4 & 30 \\
\hline & 60 & 3,120 & - & - & - \\
\hline \multirow[t]{4}{*}{2} & 15 & 0,515 & - & - & - \\
\hline & 30 & 1,860 & - & - & - \\
\hline & 45 & 1,820 & - & - & - \\
\hline & 60 & 1,820 & - & - & - \\
\hline \multirow[t]{4}{*}{3} & 15 & 0,720 & - & - & - \\
\hline & 30 & 3,395 & 14 & 12 & 26 \\
\hline & 45 & 7,980 & 33 & 3 & 36 \\
\hline & 60 & 3,435 & 18 & 8 & 26 \\
\hline
\end{tabular}


De acordo com as tabelas 20 e 47 , para a fonte de ${ }^{241} \mathrm{Am}$, o setor 2 diferiu estatisticamente do setor 3 ao nivel de 3,9\% de probabilidade em relação ao número de saúvas desta espécie, nos tempos de 15 e 30 minutos. Assim, até 30 minutos, houve um maior número de indivíduos no setor 2 que no setor 3. - Nos tempos de 45 e 60 minutos, o número de insetos foi significativamente maior no setor 2 , quando comparado com o setor 1, aos níveis de, respectivamente, 0,8 e 3,9\% de probabilidade.

$\mathrm{Na}$ presença das radiações gama do ${ }^{6}{ }^{\circ} \mathrm{Co}$, houve diferença sig nificativa entre os adultos de Atta bisphaerica Forel, 1908 nos setores 2 e 3, com predominància dos mesmos no setor 2 , aos níveis de $3,9 \%, 0,8 \%$, $0,8 \%$ e $0,8 \%$ de probabilidade nos tempos de, respectivamente, 15, 30, 45 e 60 minutos (tabelas 21 e 47 ).

Na ausència de fonte radioativa, os setores 2 e 3 diferiram estatisticamente ao nível de $3,9 \%$ de probabilidade quanto ao número de insetos após 15 e 30 minutos, havendo predominância deles no setor 2 . 0 se tor 2 também apresentou uma quantidade de insetos que foi significativamen te superior àquela do setor 1, nos tempos de 30 e 60 minutos, a um nível de probabilidade de $3,9 \%$ (tabelas 22 e 47 ).

Observando-se as tabelas $20,21,22$ e 48 , observa-se que na presença da fonte de ${ }^{60}$ Co, o setor 2 apresentou mais insetos no tempo de 15 minutos que no de 60 minutos, sendo essa diferença significativa a 3,7\% de probabilidade. Os tratamentos testemunha e fonte de ${ }^{241} \mathrm{Am}$ mostraram insetos no setor 3 , após 45 minutos, cujo número foi significativamente su perior àquele após 15 minutos, ao nível de 3,7\% de probabilidade. 
Na comparação entre os tratamentos, o setor 1, após 45 minu tos do início do teste, apresentou um número de indivíduos na presença da fonte de ${ }^{60} \mathrm{Co}$, que foi estatisticamente superior àquele constatado na presença da fonte de ${ }^{241} \mathrm{Am}$, ao nível de 4,8\% de probabilidade. Também no tempo de 45 minutos, o número de insetos no setor 3 foi estatisticamente maior na ausência de fonte radioativa que na presença da fonte de ${ }^{60}$ Co, a 3.,1\% de probabilidade. Ainda no tempo de 45 minutos, a abundância de adultos foi maior no setor 3 para o tratamento fonte de ${ }^{241} \mathrm{Am}$ do que para o tratamento fonte de ${ }^{6}$ Co, a $4,8 \%$ de probabilidade (tabelas $20,21,22$ e 49).

Pode ser observada uma tendência dos insetos desta espécie permanecerem no setor 2, de soltura. Entretanto, no tempo de 45 minutos, os insetos tenderam a se aproximar da fonte de ${ }^{6}{ }^{0}$ Co e a se afastar da fonte de ${ }^{241} \mathrm{Am}$, sendo o comportamento neste último tratamento semelhante ao do tratamento testemunha. Tal resultado diferiu do encontrado por HUG (1960), segundo BROWER (1967), que se referiu a uma resposta de aversão a radiações exibida por formigas submetidas a baixas taxas de exposição.

Este comportamento não pode ser relacionado com o efeito Ce renkov, pois, embora as radiações gama do ${ }^{6}$ Co possuam energia superior a de limiar para a produção do efeito, as operárias destas saúvas, apresentando fototatismo negativo (apêndice 5), deveriam afastar-se desta fonte.

Contudo, devido ao fato desse resultado ter sido constatado somente em um intervalo de tempo, ele pode ser considerado como ocasional, não possibilitando conclusões quanto à percepção de radiações gama por esta espécie. 
Tabela 50 - Valores de $x_{r}^{2}$ do teste de Friedman e comparações mūltiplas entre o nūmero de adultos de Camponotus rufipes (Fabr., 1775) presentes em cada.setor (S) da arena em relação aos tratamentos e tempos considerados

\begin{tabular}{|c|c|c|c|c|c|}
\hline Tratamento & Tempo $(\min )$ & $x_{r}^{2}$ & $S_{1} \times S_{2}$ & $s_{1} \times s_{3}$ & $S_{2} \times S_{3}$ \\
\hline \multirow[t]{4}{*}{$24^{11} \mathrm{Am}$} & 15 & 10,00 & 5 & 5 & 10 \\
\hline & 30 & 10,00 & 5 & 5 & 10 \\
\hline & 45 & 8,40 & 3 & 6 & 9 \\
\hline & 60 & 10,00 & 5 & 5 & 10 \\
\hline \multirow[t]{4}{*}{${ }^{60} \mathrm{Co}$} & 15 & 9,33 & 6 & 3 & 9 \\
\hline & 30 & 8,40 & 6 & 3 & 9 \\
\hline & 45 & 8,32 & 6 & 2 & 8 \\
\hline & 60 & 8,40 & 6 & 3 & 9 \\
\hline \multirow[t]{4}{*}{ Test. } & 15 & 8,32 & 6 & 2 & 8 \\
\hline & 30 & 10,00 & 5 & 5 & 10 \\
\hline & 45 & 7,60 & 7 & 1 & 8 \\
\hline & 60 & 8,40 & 6 & 3 & 9 \\
\hline
\end{tabular}


Tabela 51 - Valores de $x_{r}^{2}$ do teste de Friedman e comparações mūitiplas en tre o percentual do número total de adultos de camponotus rufipes (Fabr., 1775) encontrados em cada tempo de contagem ( $t$ ) em relação aos tratamentos e setores $(S)$ consíderados

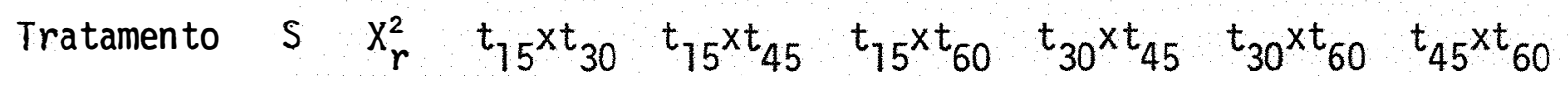

\begin{tabular}{|c|c|c|c|c|c|c|c|c|}
\hline \multirow[t]{3}{*}{$241 \mathrm{Am}$} & 1 & 2,04 & - & - & - & - & - & - \\
\hline & 2 & 3,45 & - & - & - & - & - & - \\
\hline & 3 & 4,69 & - & - & - & - & - & - \\
\hline \multirow[t]{3}{*}{${ }^{6}{ }^{0} \mathrm{Co}_{\mathrm{O}}$} & 1 & 3,31 & - & - & - & - & - & - \\
\hline & 2 & 3,13 & - & - & - & - & - & - \\
\hline & 3 & 0,68 & - & - & - & - & - & - \\
\hline \multirow[t]{3}{*}{ Test. } & 1 & 1,04 & - & - & - & - & - & - \\
\hline & 2 & 5,81 & 2 & 8 & 6 & 7 & 4 & 2 \\
\hline & 3 & 7,24 & 4 & 6 & D & 10 & 5 & 6 \\
\hline
\end{tabular}


Tabela 52 - Valores de $h$ do teste de Kruskal-Wallis e comparações mūltiplas entre os tratamentos. em relação ao percentual do nūmero total de adultos de Camponotus rufipes (Fabr., 1775) presentes nos setores $(S)$, nos tempos considerados

\begin{tabular}{|c|c|c|c|c|c|}
\hline S & Tempo (min) & $h$ & ${ }^{241} \mathrm{Am} \times{ }^{60} \mathrm{Co}$ & ${ }^{241} \mathrm{Am} \times$ Test. & ${ }^{60} \mathrm{Co} \times$ Test. \\
\hline \multirow[t]{4}{*}{1} & 15 & 0,646 & - & - & - \\
\hline & 30 & 1,683 & - & - & - \\
\hline & 45 & 1,222 & - & - & - \\
\hline & 60. & 0,383 & - & - & - \\
\hline \multirow[t]{4}{*}{2} & 15 & 2,060 & - & - & - \\
\hline & 30 & 1,007 & - & - & - \\
\hline & 45 & 2,490 & - & - & - \\
\hline & 60 & 1,125 & - & - & - \\
\hline \multirow[t]{4}{*}{3} & .15 & 4,114 & 0 & 24 & 25 \\
\hline & 30 & 5,671 & 21 & 12 & 33 \\
\hline & 45 & 9,028 & 6 & 33 & 39 \\
\hline & 60 & 6,802 & 24 & 12 & 36 \\
\hline
\end{tabular}


Pelas tabelas 23, 24, 25 e 50 pode-se observar que para os 3 tratamentos e 4 tempos considerados, o número de insetos foi significati vamente maior no setor 2 que no 3. Para o tratamento fonte de ${ }^{241} \mathrm{Am}$, nos 4 tempos, essa diferença foi significativa a 0,8\% de probabilidade. Para - tratamento fonte de ${ }^{60}$ Co, nos tempos de 15, 30 e 60 minutos, a diferença foi significativa a $0,8 \%$ de probabilidade e após 45 minutos, a 3,9\% de pro babilidade. Na ausência de fọnte radioativa, a diferença foi significati va ao nível de 3,9\% de probabilidade nos tempos de 15 e 45 minutos e a 0, $9 \%$, nos tempos de 30 e 60 minutos.

0 nümero de indivíduos não diferiu estatisticamente com o transcorrer do tempo nos 3 setores, para os 3 tratamentos, nos níveis de probabilidade normalmente considerados (tabela 51).

Pelos dados das tabelas 23, 24, 25 e 52 constata-se diferen ças significativas no número de insetos no setor 3 em relação aos tratamentos considerados. No tempo de 30 minutos, o nümero de adultos foi significativamente maior na ausência de fonte radioativa que na presença da fonte de ${ }^{6} \mathrm{Co}$, ao nível de $4,8 \%$ de probabilidade. No tempo de 45 minu tos, o tratamento testemunha apresentou um número de indivíduos que foi es tatisticamente maior, ao.nível de $4,8 \%$ de probabilidade, em relação ao tra tamento fonte de ${ }^{241}$. Também para o tempo de 45 minutos, houve diferença estatística ao nível de $0,9 \%$ de probabilidade quanto ao número de insetos presentes nesse setor em relação à fonte de ${ }^{6}{ }^{0} \mathrm{Co}$ e ausência de fonte radioativa. Neste caso, os adultos foram mais abundantes no setor 3, quando não houve exposição às radiações gama. Este mesmo fato ocorreu no tempo de 60 minutos, sendo a diferença entre o número de insetos significa 
tiva a $0,9 \%$ de probabilidade.

Pode-se constatar que nos 3 tratamentos os adultos de Camponotus rufipes (Fabr., 1775), em sua maioria, permaneceram no setor 2, de soltura. Contudo, nada se pode generalizar em relação à radioperceptividade gama desta espécie, contrariando HUG (1960), citado por BROWER (1967), que se referiu a uma resposta de aversão a radiações demonstrada por formi gas expostas a baixas taxas de exposição e também MARTINSEN e KIMELDORF (1972) que, em estimativas de limiar de exposições ou doses, indicaram que os receptores dos olhos e antenas da formiga. Camponotus herculeanus podem detectar raios $X$ e radiações beta da ordem de mrad. 
Tabela 53 - Valores de $X_{r}^{2}$ do teste de Friedman e comparaçōes mūltiplas entre o nūmero de adultos de Ceratitis capitata (Wied., 1824) presentes em cada setor (S) da arena em relação aos tratamentos e tempos considerados

\begin{tabular}{|c|c|c|c|c|c|}
\hline Tratamento & Tempo (min) & $x_{r}^{2}$ & $S_{1} \times S_{2}$ & $s_{1} \times s_{3}$ & $S_{2} \times S_{3}$ \\
\hline \multirow[t]{4}{*}{$241 \mathrm{Am}$} & 15 & 8,40 & 6 & 3 & 9 \\
\hline & 30 & 12,10 & 6 & 3 & 8 \\
\hline & 45 & 7,60 & 7 & 1 & 8 \\
\hline & 60 & 7,89 & 8 & 0 & 8 \\
\hline \multirow[t]{4}{*}{${ }^{60} \mathrm{Co}$} & 15 & 8,40 & 6 & 3 & 9 \\
\hline & 30 & 7,60 & 7 & 1 & 8 \\
\hline & 45 & 7,60 & 7 & 1 & 8 \\
\hline & 60 & 7,60 & 7 & 1 & 8 \\
\hline \multirow[t]{4}{*}{ Test. } & 15 & 8,40 & 6 & 3 & 9 \\
\hline & 30 & 9,58 & 6 & 4 & 10 \\
\hline & 45 & 7,89 & 8 & 0 & 8 \\
\hline & 60 & 8,32 & 6 & 2 & 8 \\
\hline
\end{tabular}


Tabela 54 - Valores de $x_{r}^{2}$ do teste de Friedman e comparações mūitiplas entre o percentual do número total de adultos de ceratitis capitata (Wied., 1824) encontrados em cada tempo de contagem ( $t$ ) em relação aos tratamentos e setores (S) considerados.

Tratamento $s \quad x_{r}^{2} t_{15} \times t_{30} \quad t_{15} \times t_{45} \quad t_{75} \times t_{60} \quad t_{30} \times t_{45} \quad t_{30} \times t_{60} \quad t_{45} \times t_{60}$

\begin{tabular}{|c|c|c|c|c|c|c|c|c|}
\hline \multirow[t]{3}{*}{$2{ }^{41} \mathrm{Am}$} & 1 & 2,04 & - & - & - & - & - & - \\
\hline & 2 & 9,24 & 5 & 10 & 11 & 5 & 6 & 1 \\
\hline & 3 & 10,47 & 4 & 12 & 10 & 8 & 5 & 2 \\
\hline \multirow[t]{3}{*}{${ }^{6}{ }^{\circ} \mathrm{Co}$} & 1 & 5,45 & 6 & 6 & 9 & 0 & 2 & 2 \\
\hline & 2 & 10,68 & 7 & 11 & 12 & 4 & 5 & 1 \\
\hline & 3 & 12,79 & 3 & 12 & 12 & 8 & 8 & 0 \\
\hline \multirow[t]{3}{*}{ Test. } & 1 & 7,08 & 8 & 10 & 8 & 2 & 0 & 2 \\
\hline & 2 & 11,88 & 6 & 12 & 12 & 6 & 6 & 0 \\
\hline & 3 & 11,08 & 7 & 10 & 12 & 4 & 6 & 2 \\
\hline
\end{tabular}


Tabela 55 - Valores de $h$ do teste de Kruskal-Wallis e comparações mūltiplas entre os tratamentos em relação ao percentual do número total de adultos de Ceratitis capitata (Wied., 1824) presentes nos setores $(S)$, nos tempos considerados

S Tempo (min) $\mathrm{h} \quad{ }^{241} \mathrm{Am} \times{ }^{60} \mathrm{Co} \quad{ }^{241} \mathrm{Am} \times$ Test. $\quad{ }^{60} \mathrm{Co} \times$ Test.

1

$\begin{array}{ll}15 & 1,860 \\ 30 & 1,340 \\ 45 & 0,646 \\ 60 & 0,540\end{array}$

2

$\begin{array}{lll}2 & 15 & 5,460 \\ 30 & 2,660 \\ 45 & 0,560 \\ 60 & 1,145 \\ 3 & & \\ & 15 & 1,683 \\ & & 1,220 \\ & 45 & 0,185 \\ 60 & 1,365\end{array}$

3

$\begin{array}{lll}30 & 2,660 \\ 45 & 0,560 \\ 60 & 1,145 \\ 3 & 15 & 1,683 \\ 30 & 1,220 \\ 45 & 0,185 \\ 60 & 1,365\end{array}$

27

30

3 
Com base nas tafelas 26 e 53, verifica-se que, na presença da fonte de ${ }^{241} \mathrm{Am}$, os setores 2 e 3 diferiram estatisticamente, nos 4 tempos considerados, em relação ao número de adultos, com predominância deles no setor 2. Assim, no tempo de 15 minutos, a diferença foi significativa ao nível de $0,8 \%$ de probabilidade e nos tempos de 30, 45 e 60 minutos, ao nível de 3,9\% de probabilidade. O setor 2 conteve mais insetos que o setor 1 no tempo de 60 minutos, sendo a diferença significativa a $3,9 \%$ de probabilidade.

Para o tratamento fonte de ${ }^{6 a}$ Co, o setor 2 também apresentou mais indivíduos que o setor 3, nos 4 tempos. No tempo de 15 minutos a diferença foi significativa a $0,8 \%$ de probabilidade e nos tempos de 30 , 45 e 60 minutos, ao nível de 3,9\% de probabilidade (tabelas 27 e 53).

Nota-se pelas tabelas 28 e 53 que, na auséncia de fonte radioativa, os insetos predominaram no setor 2 em relação ao setor 3 . Nos tempos de 15 e 30 minutos, a diferença entre o número de adultos nestes 2 setores foi significativa ao nivel de $0,8 \%$ de probabilidade e nos tempos de 45 e 60 minutos esta foi significativa a 3,9\% de probabilidade. 0 setor 2 ainda apresentou predomináncia de indivíduos em relação ao setor 1, a 45 minutos, ao nível de $3,9 \%$ de probabilidade.

Os insetos da presente espécie, quando expostos à fonte de ${ }^{241} \mathrm{Am}$, estiveram en maior número no setor 2 no tempo de 15 minutos que no de 60 minutos, sendo a diferença significativa a $3,7 \%$ de probabilidade. Por sua vez, o setor 3 conteve mais insetos no tempo de 45 minutos do que no de 15 minutos, com uma diferença significativa ao nível de 1,3\% de pro- 
babilidade (tabelas 26 e 54).

Na presença da fonte de ${ }^{60}$ Co, o setor 2 apresentou diferenças entre o número de adultos nos tempos de 15 e 45 minutos e 15 e 60 minu tos. No primeiro caso, o número foi maior no tempo de 15 em relação ao de 45 minutos, ao nível de $3,7 \%$ de probabilidade e no segundo, houve o mes mo comportamento, mas com significância a 1,3\% de probabilidade. Para o setor 3, o nümero de insetos foi menor no tempo de 15 minutos quando compa rado aos tempos de 45 e 60 minutos, sendo ambas as diferenças significativas ao nível de $1,3 \%$ de probabilidade (tabelas 27 e 54).

Para o tratamento testemunha nota-se, pelas tabelas 28 e 54, que a presença de insetos, no setor 2, foi maior no tempo de 15 minutos que nos tempos de 45 e 60 minutos. No setor 3, o número de adultos foi maior no tempo de 60 que no de 15 minutos. Estas diferenças foram significativas a $1,3 \%$ de probabilidade.

Observando-se a tabela 55, verifica-se que os tratamentos não diferiram estatisticamente quanto à distribuição dos insetos desta espécie pelos 3 setores., nos 4 tempos estudados, nos níveis de significância geralmente considerados. Houve, entretanto, uma tendência das moscas permanecerem no setor 2, de liberação, nos 3 tratamentos.

Assim, pelo que foi exposto, não se observaram diferenças comportamentais desses insetos quanto à exposição às radiações gama do ${ }^{243} \mathrm{Am}$ e ${ }^{60}$ Co e destes em relação ao tratamento testemunha. 


\subsection{Discussão Gera1}

- gradiente de temperatura entre os locais de colocação dos 2 termômetros (figura 1), por si somente, não foi suficiente para provocar reação comportamental nas espécies estudadas. Os diferentes comportamentos no tratamento testemunha foram devidos a fatores não controlados.

Em contradição às respostas em relação às radiações ionizan tes encontradas por HUG (1960), citado por BROWER (1967), SMITH et alii (1963), BROWER (1967), MARTINSEN E KIMELDORF (1972) e WIENDL e WALDER (1975) para várias espécies de insetos, as espécies Zabrotes sublasciatus (Boh., 1833), Acanthoscelides obtectus (Say, 1831), Callosobruchus analis (Fabr., 1775), Tribolium castaneum (Herbst, 1797), Camponotus rufipes (Fabr., 1775) e Ceratitis capitata (Wied., 1824) não apresentaram respostas comportamentais passíveis de generalizações em relação às radiações gama do ${ }^{241} \mathrm{Am}$ e ${ }^{60} \mathrm{Co}$, levando-se em conta os testes estatísticos utilizados e os níveis de significáncia geralmente tomados para eles. Tais resultados contradizem a hipótese formulada de que o comportamento divergi ria para radiações gana de diferentes energias.

A discrepancia de resultados deste estudo com os de outros autores está relacionada com as diferentes metodologias empregadas, envolvendo processo de constatação de estímulo, natureza e atividade das fontes radioativas, tempo de irradiação, etc.

Como o fototatismo das espécies Sitophilus oryzae(L., 1763) e Ephestia cautella (Walker, 1864) é, segundo STERMER (1959), negativo, 
pode-se considerar que a percepção às radiações ionizantes se deveu a um estímulo luminoso provocado por estas. radiações nos olhos, conforme citaram SMITH et alii (1963) e SMITH e KIMELDORF (1964) em estudos com mariposas, MARTINSEN e KIMELDORF (1972) com formigas da espécie Camponotus hercu leanus e WIENDL e WALDER (1975) com o caruncho sitophilus zeamais. E, devido ao fato da energia das radiações gama do ${ }^{241} \mathrm{Am}$ estar abaixo daquela do limar para o efeito Cerenkov na água, supõe-se que este efeito tenha ocorrido por interação das radiações com outro componente ocular, de maior Índice de refração que o da água. A produção de fluorescência por intera ção das radiações ionizantes com os componentes oculares foi também uma hipótese de detecção das radiações ionizantes levantada por SMITH e KIMELDORF (1964) e WIENDL e WALDER (1975).

Para as espécies onde se observou percepção, nota-se que a detecção das radiações ionizantes se processa de maneira semelhante a das radiações infravermelho incoerentes, pois estas últimas, segundo CALLAHAN (1967), são detectadas, teoricamente, pelos olhos compostos e ocelos. 


\section{CONCLUSOES}

Com base nos resultados encontrados e nas condições de realização do experimento, pode-se concluir que:

19̣) o limiar de dose de radiações gama necessário para provocar um estímulo comportamental varia de espécie para espécie de inseto;

20) as espécies Zabrotes sub fasciatus (Boh., 1833), Acanthoscelides obtectus (Say, 1831), Callosobruchus analis (Fabr., 1775), Tribolium castaneum (Herbst, 1797), Camponotus rufipes (Fabr., 1775), Ceratitis capitata (Wied. 1824) e Atta bisphaerica Forel, 1908 não apresentaram respostas comportamentais passiveis de generalizações, quando expostas às radiações gama do ${ }^{241} \mathrm{Am}$ e ${ }^{60} \mathrm{Co}$;

30) para adultos das espécies Sitophilus oryzae (L., 1763) 
e Ephestia cautella (Walker, 1864), em quem se observou percepção às radiações ionizantes, a atividade da fonte radioativa foi relevante em comparação com a energia das radiações emitidas pela mesma; isto significando que o importante é a dose absorvida de radiações;

49̣) para as espécies que apresentaram resposta às radiações ionizantes, a percepçäo se processou ou através de um estímulo visual direto ou por um estímulo luminoso nos olhos, provavelmente por produção de radiações Cerenkov resultantes da interação das radiações ionizantes com algum componente ocular, exceto a água. 


\section{SUMMARY}

The objective of the present work was to prove the existence of a perception for ionizing radiation by insects and determine its processing mechanism. Another objective was to check if such perception induces the insects to keep away from the radiation source, proving therefore a protection against the harms caused by ionizing radiation, or else the stimulus for such behaviour is similar to that caused by light radiations.

$$
{ }^{60} \mathrm{Co} \text { and }{ }^{241} \mathrm{Am} \text { were used as gamma radiation sources, the }
$$

${ }^{60} \mathrm{Co}$ source of $0.435 \mathrm{mCi}$ and the ${ }^{241} \mathrm{Am}$ of $99.68 \mathrm{mCi}$ activity. Adult insects of the species Acanthoscelides obtectus (Say, 1831), Zabrotes subfasciatus (Boh., 1833), Callosobruchus analis (Fabr., 1775), Sitophilus oryzae (L., 1763), Ephestia cautella (Walker. 1864), Tribolium castaneum (Herbst, 1797), Ceratitis capitata (Wied., 1824) and workers of Atta bisphaerica (Forel, 1908) and Camponotus rufipes (Fabr., 17751 were used 
with the following treatments: exposure to ${ }^{6 a} \mathrm{Co}$ and ${ }^{241} \mathrm{Am}$ radiation and non-exposure control].

A total of approximately 50 insects per replication was released in the central region of an opaque white wooden barrier divided into 3 sections with the same area $-60.0 \mathrm{~cm}$ diameter and $7.5 \mathrm{~cm}$ height covered with a nylon screen. 5 replications per treatment were made and the distribution of the insects was evaluated by photographs taken at 15 , 30,45 and 60 minutes after release.

The behaviour of species Zabrotes subfasciatus (Boh., 1833). Acanthoscelides ob.tectus (Say, 1831), Callosobruchus analis (Fabr., 1775), Tribolium castaneum (Herbst, 1797), Camponotus rufipes (Fabr., 1775), Ceratitis capitata (Wied., 1824 ) and Atta bisphaerica Forel, 1908 in relation to ${ }^{60} \mathrm{Co}$ and ${ }^{241} \mathrm{Am}$ gamma radiation were not responsive enough to lead to generalization. However, Sitophilus oryzae (L., 1763) and Ephestia cautella. (Walker, 1864) showed some response to ${ }^{241}$ Am gamma radiation, i.e. negative tactism.

It was concluded that ionizing radiations can be detected by insects through direct visual stimulus or by visual stimulus resulting from interaction of radiation - Cerenkov radiation - with some other occular component with a refraction index greater than water. Also, the activity of the radioactive source with regard to perception for ionizing radiation, is of relevance in comparison with the energy of the radiation emitted by same, or in other words, what really matters is the radiation dose absorbed. 


\section{LITERATURA CITADA}

BACHOEER, C.S. e S.E. WITTRY - 1962." Comparison of electroretinal response to X-ray and to light. Radiation Research, 17: 1-10.

BERTHOLF, L.M. - 1931. Reactions of the honeybee to light. Joumal of Agricultural Research, 42(7):379-419.

BROWER, J.H., 1967. A possible radiation avoidance response exhibited by an insect population in nature. Die Naturwissenschaften, 2: 39-40.

BURSELL, E. - 1970. An introduction to insect physiology. London, Academic Press Inc. Ltd. 276p.

CALLAHAN, P.S. - 1967. Insect molecular bioelectronics: a theoretical and experimental study of insect sensillae as tubular waveguides, with particular emphasis on their dielectric and thermoelectret properties. 
Miscellaneous Publications of the Entomological Society of America, 5 (7): $315-347$.

CAMPOS, H. de - 1979. Estatistica experimental não paramétrica. 3a. edição. Piracicaba, Departamento de Matemática e Estatística, ESALQ/ USP. $343 p$.

GALLO, D.; O. NAKANO; F.M. WIENDL; S. SILVEIRA NETO e R.P.L. CARVALHO - 1970. Monual de entomologia - pragas das plontas e seu controle. São Paulo, Editora Agronómica Ceres. $\quad 858$ p.

GELSEMA, W.J.; C.L. de LIGNY, J.B. LUTEN e F.G.A. VOSSENBERG - 1975. The use of the Cerenkov effect in the counting of $\beta$-and $\gamma$-emitting radionuclides. International Joumal of Applied Radiation and Isotopes, 26: 443-450.

LIPETZ, L.E. - 1955 a. The X-ray and radium phosphenes. Br. J. Ophthal, $39: 577-598$.

LIPETZ, L.E. - 1955 b. Electrophysiology of the X-ray phosphene. Radiation Research, 2: $306-329$.

MARTINSEN, D.L. e D.J. KIMELDORE - 1972. The prompt detection of ionizing radiations by carpenter ants. Biol. Bulz., 143: 403-419.

MARZKE, E.O.; M.W. STREET; M.A. MULLEIV e T.L. MCCRAY - 1973. Spectral responses of six species of stored-product insects to visible light. 
J. Georgia Entomol. Soc., 8[3]: 195-200.

NASCIMENTO FILHO, V.F. do - 1975. Uso de uma fonte externa $\left(^{60}\right.$ Col para a determinação da eficiência de detecção de ${ }^{32} \mathrm{P}$ pelo efeito Cerenkov, em extratos de solo. Piracicaba, ESALQ/USP, 151p. (Dissertação de Mes trado].

PARKER, R.P. e R.H. ELRICH - 1970. Cerenkov counting as means of assaying B-emitting radionuclides. In: BRANSONE JR., E.D., ed. The current status of Ziquid scintiliation conmting. New York, Grune \& Straton, p. $110-122$.

PHILLIS, W.A. e H.R. AGEE - 1976. Spectral sensitivity and variations in visual sensitivity of the colonized screw-worm fly, Cochliomyia hominivorax (Coquerel), as measured with electroretinogram. J. Georgia Entomor. Soc., 11(3): 243-246.

ROSS, H.H., 1969. Measurement of $\beta$-emitting nuclides using Cerenkov radiation. Analitical Chemistry, 41(10): 1260-1265.

ROSS, H.H. e G.T. RASMUSSEN - 1974. Modern techniques and applications in Cerenkov counting. In: STANLEY, P.E. e SCOGGINS, B.A., ed. Liquid scintizlation counting: recent developments. New York. Academic Press, Inc., p. 363-382.

SMITH, J.C.; D.J. KIMELDOPF E E.L. HUNT - 1963. Motor responses of moths 
to low-intensity X-ray exposure. Science, 140: 805-806.

SMITH, J.C. e D.J. KIMELDORF - 1964. The bioelectrical response of the insect eye to beta-radiation. J. Ins. Physiol., 10: 839-847.

STERMER, R.A. - 1959. Spectral response of certain stored-product insects to electromagnetic radiation. Joumal of Economic Entomology, $52(5): 888-892$.

WEISS, H.B.; F.A. SORACI e E.E. MCCOY JR. - 1942. The behavior of certain insects to various wavelenghts of light. Journal of New York Entomological Society, 50: 1-35.

WIENDL, F.M. e J.M.M. WALDER - 1975. Perception of gcomma radiation by acults of Sitophilus zeamais Mots. Piracicaba, CENA. 11p. Boletim Científico-031.

YINON, U. - 1970. The visual mechanisms of Tenebrio molitor - some aspects of the spectral response. J. Exptl. Biol., 53: 221-229. 


\section{APENDICE 1}

Limites da distribuição.de $X_{r}^{2}$ no teste de Friedman

$P_{0}\left[x_{r}^{2} \geq X_{r}^{2}\right)=\alpha$

$k=$ número de tratamentos

$\mathrm{n}$ = nümero de repetições por tratamento

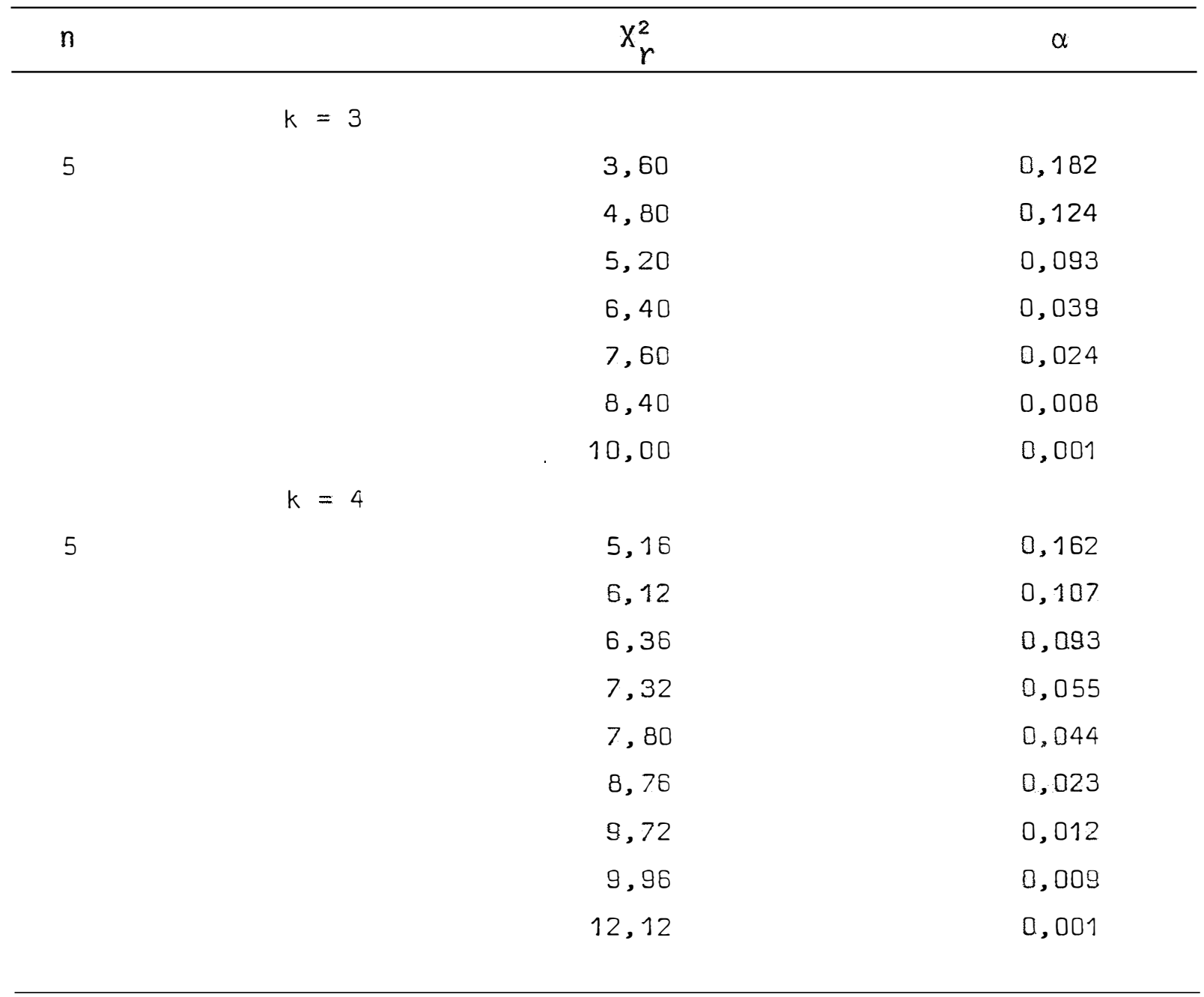

Esta tabela foi adaptada por CAMPOS (1979), de OWEN (1962), para $k=3$, e de HOLLANDER e WOLFE (1973), para $k=4$. 


\section{APENDICE 2}

Diferença mínima significativa $\left(\Delta_{1}\right)$ para as comparações múl tiplas, baseadas no teste de Friedman, envolvendo todos os pares $(i, j)$ de tratamentos.

$$
\begin{aligned}
& P_{0}\left(\left|R_{i}-R_{j}\right| \geq \Delta_{1}\right)=\alpha \\
& k=\text { número de tratamentos } \\
& n=\text { número de repetições por tratamento }
\end{aligned}
$$

\begin{tabular}{|c|c|c|c|}
\hline$n$ & & $\Delta_{1}$ & $\alpha$ \\
\hline \multirow{6}{*}{5} & $k=3$ & & \\
\hline & & 8 & 0,039 \\
\hline & & 9 & 0,008 \\
\hline & $k=4$ & & \\
\hline & & 11 & 0,037 \\
\hline & & 12 & 0,013 \\
\hline
\end{tabular}

Tabela adaptada por CAMPOS (1972), de HOLLANDER e WOLFE (1973). 


\section{APENDICE 3}

Limites da distribuição de $\mathrm{H}$ no teste de Kruskal-Wallis

$$
P_{0}(H \geq h)=\alpha
$$

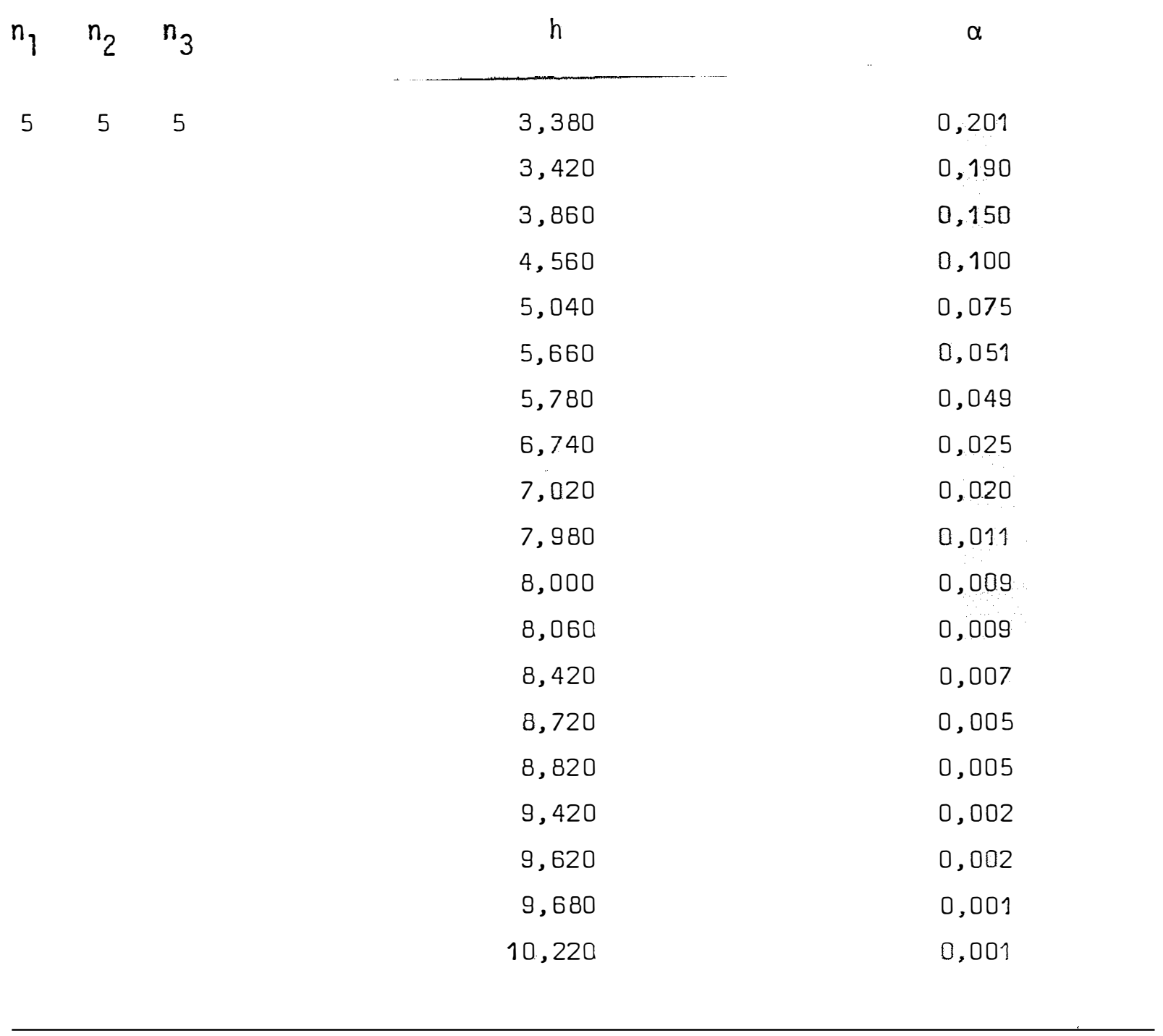

Esta tabela foi adaptada por CAMPOS (1979), de HOLLANDER e WOLFE (1973). 


\section{APENDICE 4}

Diferença mínima significativa $(\Delta)$ para as comparações múltiplas, baseadas no teste de Kruskal-Wallis, envolvendo todos os pares $(i, j)$ de tratamentos e com $n_{1}=n_{2}=\ldots=n_{k}=n$.

$P_{0}\left(\left|R_{i}-R_{j}\right| \geq \Delta\right\}=\alpha$

$k=$ nümero de tratamentos

$\mathrm{n}$ = número de repetições por tratamento

$n$

$\triangle$

$\alpha$

$k=3$

5

33

35

39
0,048

0,031

0,009

Tabela adaptada por CAMPOS (1979), de HOLLANDER e WOLEE (1973). 


\section{APENDICE 5}

\section{DETERMINAÇAO DO FOTOTATISMO DE SAOVAS}

Cada uma das 4 repetiçães constou da liberação de, aproximą damente, 30 operárias da espécie Atta sexdens rubropilasa Forel, 1908 na região central de um tubo cilíndrico de lucite com $100,0 \mathrm{~cm}$ de comprimento por 4,5 cm de diámetro, demarcado de 10 e $10 \mathrm{~cm}$. Em uma das extremidades colocou-se uma lámpada fluorescente, luz do dia de $15 \mathrm{~W}$, fazendo-se a contagem do nümero de insetos em cada setor nos tempos de $10,20,30,40,50$ e 60 minutos. Em cada extremidade do tubo foram colocados termómetros que foram lidos nos tempos de contagem dos insetos.

o teste foi efetuado em cámara de ambiente controlado, com $27 \pm 3^{\circ} \mathrm{C}$ e $75 \pm 5 \%$ de umidade relativa e os resultados encontram-se tabula dos nas tabelas seguintes. 
Distribuição, em relação ao tempo, de operāria da espēcie Atta sexdens rubropilosa Forel, 1908 submetidas à Juz, considerando-se a porcentagem do nümero total de insetos em cada repetição e tempo

\begin{tabular}{|c|c|c|c|c|c|c|c|c|}
\hline \multirow{2}{*}{ Repetição } & \multirow{2}{*}{\multicolumn{2}{|c|}{$\begin{array}{c}\text { Distāncia } \\
\text { da luz } \\
(\mathrm{cm})\end{array}$}} & \multicolumn{6}{|c|}{ Tempo (min) } \\
\hline & & & 10 & 20 & 30 & 40 & 50 & 60 \\
\hline \multirow[t]{3}{*}{1} & 0 a & 40 & 0,0 & 6,7 & 10,0 & 13,3 & 30,0 & 30,0 \\
\hline & $40 a$ & 60 & 93,3 & 63,3 & 56,7 & 33,3 & 30,0 & 20,0 \\
\hline & $60 a$ & 100 & 6,7 & 30,0 & 33,3 & 53,3 & 40,0 & 50,0 \\
\hline \multirow[t]{3}{*}{2} & 0 a & 40 & 0,0 & 10,3 & 3,4 & 24,1 & 20,7 & 27,6 \\
\hline & $40 a$ & 60 & 86,2 & 62,1 & 51,7 & 37,9 & $24 ; 1$ & 27,6 \\
\hline & $60 a$ & 100 & 13,8 & 27,6 & 44,8 & 37,9 & 55,2 & 44,8 \\
\hline \multirow[t]{3}{*}{3} & 0 a & 40 & 0,0 & 0,0 & 0,0 & 0,0 & 0,0 & 3,1 \\
\hline & $40 a$ & 60 & 93,8 & 87,5 & 75,0 & 84,4 & 75,0 & 84,0 \\
\hline & $60 a$ & 100 & 6,2 & 12,5 & 25,0 & 15,6 & 25,0 & 12,5 \\
\hline \multirow[t]{3}{*}{4} & $0 a$ & 40 & 0,0 & 7,4 & 0,0 & 3,7 & 25,9 & 18,5 \\
\hline & $40 a$ & 60 & 81,5 & 63,0 & 70,4 & 48,1 & 33,3 & 25,9 \\
\hline & 60 & 100 & 18,5 & 29,6 & 29,6 & 48,1 & 40,7 & 55,5 \\
\hline
\end{tabular}


Temperaturas, em ${ }^{\circ} \mathrm{C}$, nas extremidades do tubo, nos vārios tempos de contagem

\begin{tabular}{|c|c|c|c|c|c|c|c|}
\hline \multirow{2}{*}{ Repetição } & \multirow{2}{*}{$\begin{array}{c}\text { Distāncia } \\
\text { da luz } \\
(\mathrm{cm})\end{array}$} & \multicolumn{6}{|c|}{ Tempo (min) } \\
\hline & & 10 & 20 & 30 & 40 & 50 & 60 \\
\hline \multirow[t]{2}{*}{1 e 2} & 0 & 28,0 & 28,5 & 28,5 & 28,5 & 28,5 & 28,5 \\
\hline & 100 & 27,0 & 27,0 & 27,0 & 27,0 & 27,0 & 27,0 \\
\hline \multirow[t]{2}{*}{3 e 4} & 0 & 28,0 & 28,5 & 29,0 & 29,0 & 29,0 & 29,0 \\
\hline & 100 & 27,0 & 27,0 & 28,0 & 27,5 & 27,0 & 27,5 \\
\hline
\end{tabular}

Pelos resultados, nota-se que em todos os tempos de contagem e repetições, a incidēncia de saúvas foi maior na região de 60 a $100 \mathrm{~cm}$ que na de 0 a $40 \mathrm{~cm}$. E O gradiente de temperatura entre as extremidades do tubo não foi significativamente importante nesse tipo de comportamento (1).

Portanto, as operárias da saúva Atta sexdens rubropilosa Fo rel, 1908 apresentam fototatismo negativo.

(1) MARICONI, F.A.M., 1980. Comunicąão pessoal. 